\title{
The contribution of molecular data to our understanding of cephalopod evolution and systematics: a review
}

\author{
A. Louise Allcock ${ }^{\mathrm{a} *}$, A. Lindgren ${ }^{\mathrm{b}}$ and J.M. Strugnell ${ }^{\mathrm{c}}$ \\ ${ }^{a}$ Ryan Institute and School of Natural Sciences, National University of Ireland Galway, Galway, \\ Ireland; ${ }^{b}$ Department of Biology, Portland State University, Portland, OR, USA; ${ }^{c}$ Department of \\ Genetics, La Trobe Institute for Molecular Science, La Trobe University, Bundoora, Victoria, \\ Australia
}

(Received 28 January 2013; accepted 10 July 2013; first published online 18 February 2014)

\begin{abstract}
The first DNA sequence of a cephalopod was published in 1983 and the first molecular paper focusing on cephalopods was published in 1994. In this review we trace progress in the field. We examine the placement of Cephalopoda with respect to other molluscan classes and we examine relationships within Cephalopoda. We provide a summary tree of the relationships between cephalopod orders and we examine relationships of taxa within each of these orders. Although much knowledge has been gained over the past 20 years, deeper-level relationships are still not well understood and there is still much scope for further research in this field. Genomic studies are likely to contribute significantly to our knowledge in the future.
\end{abstract}

Keywords: Mollusca; Cephalopoda; molecular systematics; phylogenetics; taxonomy

\section{Cephalopods: an introduction}

The Class Cephalopoda (octopuses, squids, bobtail squids, cuttlefishes and nautiluses) contains an astonishing variety of morphological diversity. The class contains representatives that inhabit environments from the tropics to the polar regions, pelagic and benthic habitats and surface waters to the deepest seas. The group contains species with total sizes that range from $\sim 20 \mathrm{~m}$ (giant squid) to $\sim 2 \mathrm{~cm}$ (pygmy squid), species that exhibit the ability to change colour and texture and others that display marked sexual dimorphism of body size. Although there are only about 800 species of cephalopod, their body forms differ so widely that morphological homologies are often hard to recognize. In addition, the fact that most cephalopods lack a shell, possess few hard structures and are known to often distort in size, colour and shape on preservation, further adds difficulty to determining and measuring homologous characters.

Cephalopoda contains the hard-shelled nautiluses, living fossils, today represented by only a few species and contained within their own subclass (Nautiloidea). By far the majority of extant cephalopods are contained within the subclass Coleoidea, which comprises the octopuses, bobtail squids, oceanic squids and cuttlefishes. Coleoidea comprises a number of lineages well recognized as representing monophyletic groups (see Table 1). Some of these major lineages of coleoid cephalopods are species rich,

*Corresponding author. Email: louise.allcock@gmail.com 
including the octopods ( $\sim 300$ species $)$ and the cuttlefishes ( $\sim 120$ species); however, other ancient lineages today contain only a single known extant species possessing unique morphological characteristics, for example the feeding filaments of the vampire squid, Vampyroteuthis infernalis, and the internal coiled shell of the ram's horn squid, Spirula spirula. Because of the very large number of morphological differences between the many coleoid lineages, the lack of shared characters, the uncertainty regarding character homology and the differing rates of evolution across groups, biologists have struggled to understand many of the evolutionary relationships among taxa.

The phylogenetic uncertainty between the major lineages of Coleoidea is also influenced by similar uncertainty within the phylum Mollusca, where Cephalopoda is just one of eight extant classes. Relationships among these classes have long been controversial. For example, some authors (Hatscheck 1891; Runnegar and Pojeta 1974; Scheltema 1993) propose the clade Aculifera containing the classes Neomeniomorpha (= solenogastres), Chaetodermomorpha (= caudofoveates) and Polyplacophora. In contrast, others (Salwini-Plawen and Steiner 1996; Haszprunar 2000) propose the clade Testaria: a sister-taxon relationship between Conchifera and Polyplacophora. In this scenario, Aplacophora (= Neomeniomorpha + Chaetodermorpha) is sister to Testaria. Conchifera is a hypothesized clade (Gegenbaur 1878; Runnegar and Pojeta 1974) containing the five classes whose shell originates with an ectodermal invagination (Scheltema 1993), i.e. Monoplacophora, Cephalopoda, Bivalvia, Gastropoda, Scaphopoda. The clade Cyrtosoma comprises a sister-taxon relationship between Cephalopoda and Gastropoda and Diasoma comprises sister-taxon relationship between Scaphopoda and Bivalvia (Salwini-Plawen 1980; Runnegar and Pojeta 1985, 1992). There are other hypotheses and there has been extensive debate with conflicting support for various topologies from both morphological (including palaeontological) and molecular studies (e.g. Steiner and Dreyer 2003; Sigwart and Sutton 2007; Kocot et al. 2011; Smith et al. 2011).

In this review, we consider the molecular work that has led to our understanding of the phylogenetic position of Cephalopoda among other molluscan classes, how its position informs higher-level relationships within the class, the molecular studies that have sought to clarify the relationships among higher cephalopod taxa, and the research investigating relationships within cephalopod higher taxa. To aid clarity, we include a table of higher-taxon names and a brief description of how we apply them in this review (Table 1).

\section{Cephalopods in the wider molluscan tree}

The first published cephalopod DNA sequence is that of the 5S ribosomal RNA (rRNA) gene of Illex illecebrosus (Walker and Doolittle 1983); 5S rRNA is a small (approximately 120 base pairs (bp)) ribosomal gene located in the nuclear genome in a transcription unit that also comprises 5.8S rRNA, 18S rRNA, 28S rRNA and the internal and external transcribed spacers. This early study published sequences of 5S rRNA from four species and added them to an existing database of seven others. Comparison of the sequences, which included a bivalve (Mytilus edulis) and a gastropod (Helix pomatia) is not very revealing. However, the potential of the method was recognized. Shortly afterwards, the 5S rRNA sequence of Octopus vulgaris was sequenced (Ohama et al. 1984). By this time, sequences of 5S rRNA from 54 metazoan species were available and the authors constructed trees using the relatively simple 


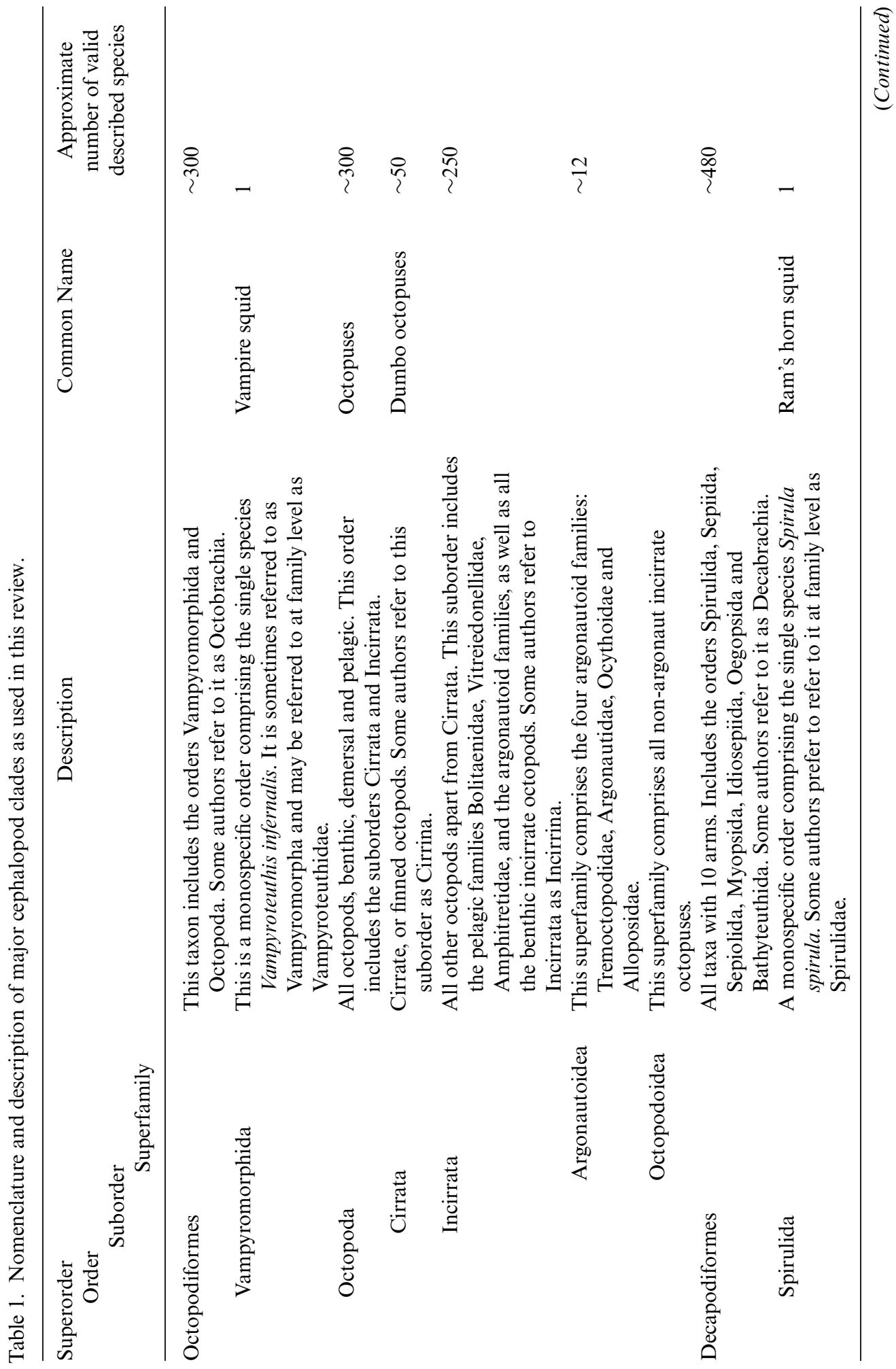


1376 A.L. Allcock et al.

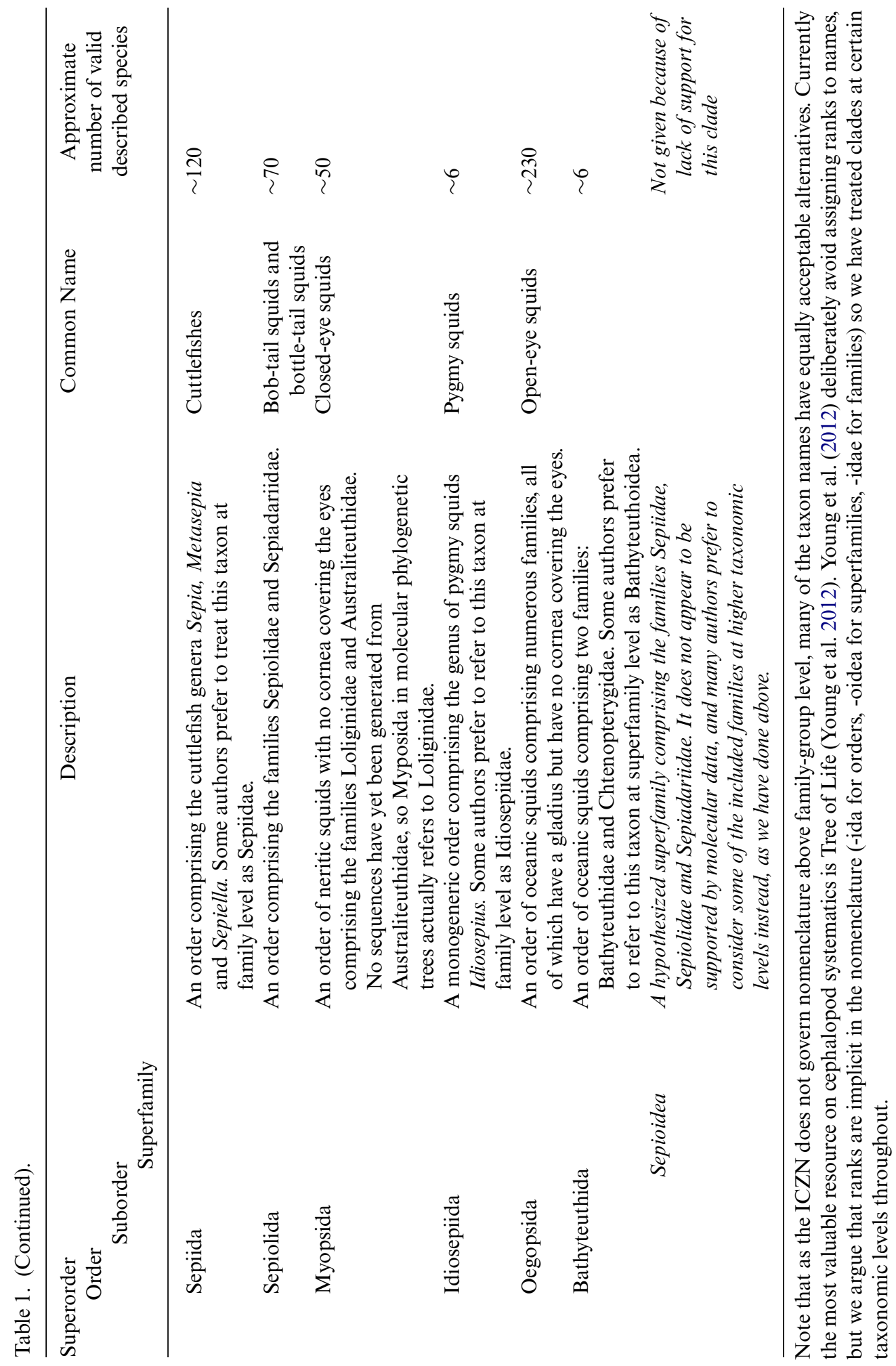


distance-based clustering methods, UPGMA and WPGMA, which were the methods available at the time. They found Octopus vulgaris to be the sister taxon to the Illex sequence but this clade was sister taxon to a sea cucumber rather than to other molluscs, showing the limited resolving power of 5S rRNA at deep taxonomic levels. The single bivalve (Mytilus edulis) fell in a clade comprising a brachiopod, a bryozoan, a sipunculid and an annelid, while the gastropods (Helix pomatia and Arion rufus) formed a clade with a nemertine worm.

As molecular methodologies developed, and universal primers applicable to wide groups of metazoans (and indeed other groups) were published, the resolving power of phylogenetic methods at deep taxonomic levels improved. Attempts were made to resolve aspects of molluscan phylogeny using the 18S rRNA gene (Rosenberg et al. 1994; Winnepenninckx et al. 1996), but none included cephalopods. Rosenberg et al. (1997) attempted to clarify molluscan relationships using the D6 region of the 18S rRNA gene, and included several cephalopods, with particular focus on myopsid squids (six species: Loligo forbesii, Doryteuthis opalescens, Doryteuthis pealeii, Doryteuthis pleii, Loliolus uyii, Uroteuthis edulis) but also including a cuttlefish (Sepia officinalis) and two nautilus species (Nautilus pompilius and Nautilus macromphalus). The study included chitons, scaphopods, bivalves and gastropods (i.e. five classes) and used annelids as an outgroup. Cephalopods formed a clade in the resulting tree, but there was no resolution among molluscan classes, so the relationship between cephalopods and other molluscs remained obscure.

Steiner and Dreyer (2003) found cephalopods to be the sister taxon of scaphopods, hence refuting both the Diasoma and Cyrtosoma hypotheses. This study was also based on 18S rRNA and included 17 scaphopods, 17 bivalves, seven gastropods and four cephalopods and was rooted with three polyplacophorans. The uneven taxon sampling and the fact that two of the cephalopods (both Nautilus species) are on long branches may have affected the results.

In an attempt to provide better resolution, Passamaneck et al. (2004) compiled a dataset comprising 32 molluscan ingroup taxa in seven classes (all classes except Monoplacophora). The authors sequenced $3035 \mathrm{bp}$ of $18 \mathrm{~S}$ rRNA and $5288 \mathrm{bp}$ of $28 \mathrm{~S}$ rRNA. Because of unalignable regions, they included only $1520 \mathrm{bp}$ and 2452 bp of each gene, respectively. As cephalopod representatives they included a nautilus (Nautilus pompilius), the vampire squid (Vampyroteuthis infernalis), two oegopsids (Histioteuthis sp. and Abraliopsis sp.), a myopsid (Doryteuthis pealeii) and two octopods (Muusoctopus yaquinae and Graneledone pacifica). Like Rosenberg et al. (1997), this study found strong support for cephalopod monophyly, although relationships within the cephalopod clade did not reflect well-established groups. For example, the oegopsids did not form a monophyletic group, although this may not be altogether surprising since the Histioteuthis 28S rRNA sequence may be a contaminant (see Mallatt et al. 2010). Also, bivalves, which are united by a strong morphological synapomorphy (i.e. two shells), were not recovered as monophyletic. Problems identified with the data included rate heterogeneity and base composition heterogeneity, which may have led to long-branch attraction, a tangible problem in real datasets, including those using 18S rRNA (Anderson and Swofford 2004). The maximum parsimony tree differed from their maximum likelihood tree and this might have resulted from the greater susceptibility of parsimony methods to long-branch attraction, the process whereby rapidly evolving lineages, which may be in fact distantly related, are inferred to be closely related (Felsenstein 2004). Passamaneck et al. 
(2004) used Shimodaira-Hasegawa tests to support/refute well-known hypotheses of molluscan evolution; however, the number of tests is too great to report here, especially given the limited support for deep relationships in their trees.

Giribet et al. (2006) published the first pan-molluscan phylogenetic study to include Monoplacophora. Their dataset comprised $6500 \mathrm{bp}$ of data derived from complete 18S rRNA, $\sim 3$ kilobases of $28 \mathrm{~S}$ rRNA, histone $\mathrm{H3}$, and partial sequences of $16 \mathrm{~S}$ rRNA and cytochrome oxidase I (COI) and incorporated 101 molluscan species across all eight classes, including 18 cephalopod species. The monoplacophoran DNA was degraded and the authors amplified only the $28 \mathrm{~S}$ rRNA $(1.2 \mathrm{~kb})$ of this specimen. Because the monoplacophoran sequence fell in a clade of chitons, the authors proposed a clade "Serialia", the name reflecting the repeating plates of chitons, and the serially repeated organs of Monoplacophora. This relationship overshadowed other aspects of the phylogeny. Unfortunately, it was later discovered that the monoplacophoran sequence was in fact a chimeric sequence; i.e. it comprised both monoplacophoran and contaminant polyplacophoran sequences. This undoubtedly artificially influenced the phylogenetic placement of the monoplacophoran in the tree. The tree had several additional problems: Bivalvia and Gastropoda were both polyphyletic and there was little or no support for higher-level relationships, so we learn little about the evolutionary origins of Cephalopoda. Problems with the tree might be associated with the method of alignment and analysis (direct optimization in POY; Wheeler 1996; Wheeler et al. 2002), which is discussed in more detail later, the retention of difficult-to-align data (also discussed later), but may simply result from saturation of the data, which was not discussed, but is likely considering the breadth of the study and the included genes. However, the study by Giribet et al. (2006) is not alone. There have been many studies that have failed to find support for clades that are well established on morphological grounds (e.g. Colgan et al. 2008; Goloboff et al. 2009; Mallatt et al. 2010, 2012; Wilson et al. 2010).

Wilson et al. (2010) used the same five genes (18S rRNA, 28S rRNA, histone H3, $16 \mathrm{~S}$ rRNA, COI) and re-sequenced a monoplacophoran to solve the chimeric problem. They also failed to recover molluscan monophyly and considered that long-branch attraction might be part of the problem. They also recovered the clade Serialia (with chitons sister to Monoplacophora) in one, but not all, of their analyses. However, their tree made little morphological sense, failing to recover any of the molluscan relationships commonly hypothesized on morphological grounds.

Colgan et al. (2008) included Nautilus in analyses investigating the relationships between molluscs, annelids and arthropods. They used the genes 18S rRNA, 28S rRNA, U2 spliceosomal RNA (snRNA), histone H3 and COI, including regions that did not clearly align, and also third codon positions of rapidly evolving genes such as COI. Interestingly, because of the problems previous authors had encountered with $18 \mathrm{~S}$ rRNA, they also built trees excluding this gene. However, this had minimal effect on the topology. Although they felt their topography showed "good agreement with the morphological allocations for the various phyla", they did not in fact find Mollusca to be monophyletic. They concluded that some of the problems encountered were associated with "long-branch" taxa, i.e. those lineages that have evolved independently for a long time and have no close living relatives, such as Nautilus. This would have been exacerbated by the fact that they included no other cephalopod taxa in their analysis despite cephalopod sequences being available for four (18S rRNA, 28S rRNA, histone $\mathrm{H} 3$ and COI) of the five genes they sequenced (Lindgren et al. 2004). 
Goloboff et al. (2009) took a radical approach to taxon sampling and extracted information on 13 genes from GenBank, including every taxon that had been sequenced for one of more of those genes. Some genes were from plastid genomes, but the metazoan dataset included six genes. The authors estimated that on average only one-fifth of the genes were available for each taxon. The number of molluscs included in the dataset was 2578. Despite the very large dataset, which they analysed using the very fast sectorial search method available in TNT, a parsimony-based analysis program (Goloboff et al. 2004), they still did not recover a monophyletic Mollusca. Instead they found that Scaphopoda and Bivalvia were successive sister groups of other invertebrate phyla, while the remaining molluscan classes formed a monophyletic group.

Mallatt et al. (2010) explored the metazoan tree using almost complete rRNA genes (18S and 28S). They included 197 taxa across the metazoan tree and they also did not recover a monophyletic Mollusca. They identified a "mongrel assemblage", which they felt arose from problems with long-branch attraction, and this included Vampyroteuthis and Nautilus (the only two cephalopods included). The remaining molluscs did not form a monophyletic group either: rather they formed a clade that included annelids and brachiopods. Polyplacophora and Bivalvia were supported as sister clades, but together they were sister to the annelids, with brachiopods and then gastropods as successive sister clades to this. Because of GC bias (base composition heterogeneity) in their dataset (bilaterians were AT-rich), the authors were concerned that some non-bilaterians that were also AT-rich may have been artificially attracted towards the Bilateria clade, producing a phylogenetically inaccurate tree.

Undeterred, Mallatt et al. (2012) repeated their analysis with more taxa (371), basing their alignment on rRNA secondary structure to improve its quality. Unfortunately they found that more taxa did not improve the phylogenetic resolution and they felt that problems resulted from base-compositional heterogeneity and also from including too many highly divergent sequences, which unfortunately included the cephalopods. The cephalopods, which included two octopods, Benthoctopus and Graneledone, and two squids, Loligo and Abraliopsis, fell in a clade with a chaetognath, onychophorans and pauropods in a position far removed from other molluscs. There was no support for the position of the scaphopods. The remaining molluses (Bivalvia, Gastropoda, Polyplacophora and Monoplacophora) grouped together in a clade that was sister to a clade containing most annelids.

Phylogenomic studies have recovered a monophyletic Mollusca. Dunn et al. (2008) based an analysis on 71 metazoan taxa and 150 genes. The single cephalopod representative in this case (Euprymna scolopes) fell as sister taxon to Chaetoderma nitidulum (Caudofoveata), with a chiton (Chaetopleura apiculata) as successive sister taxon. These three species formed the clade that was sister to the bivalves and gastropods, themselves sister clades. Although the internal topology of the Mollusca clade was not highly satisfactory from a morphological viewpoint, this study illustrated the potential of phylogenomic methods in reconstructing the metazoan tree of life, by situating a monophyletic Mollusca in Lophotrochozoa.

Kocot et al. (2011) and Smith et al. (2011) also tackled the problem with a phylogenomic approach. Kocot et al. (2011) included seven of the eight molluscan classes (excluding Monoplacophora) comprising 42 operational taxonomic units (OTUs), and used 308 genes totalling 84,614 amino acid positions. Smith et al. (2011) included representatives from all classes, including 35 OTUs, sequences from 


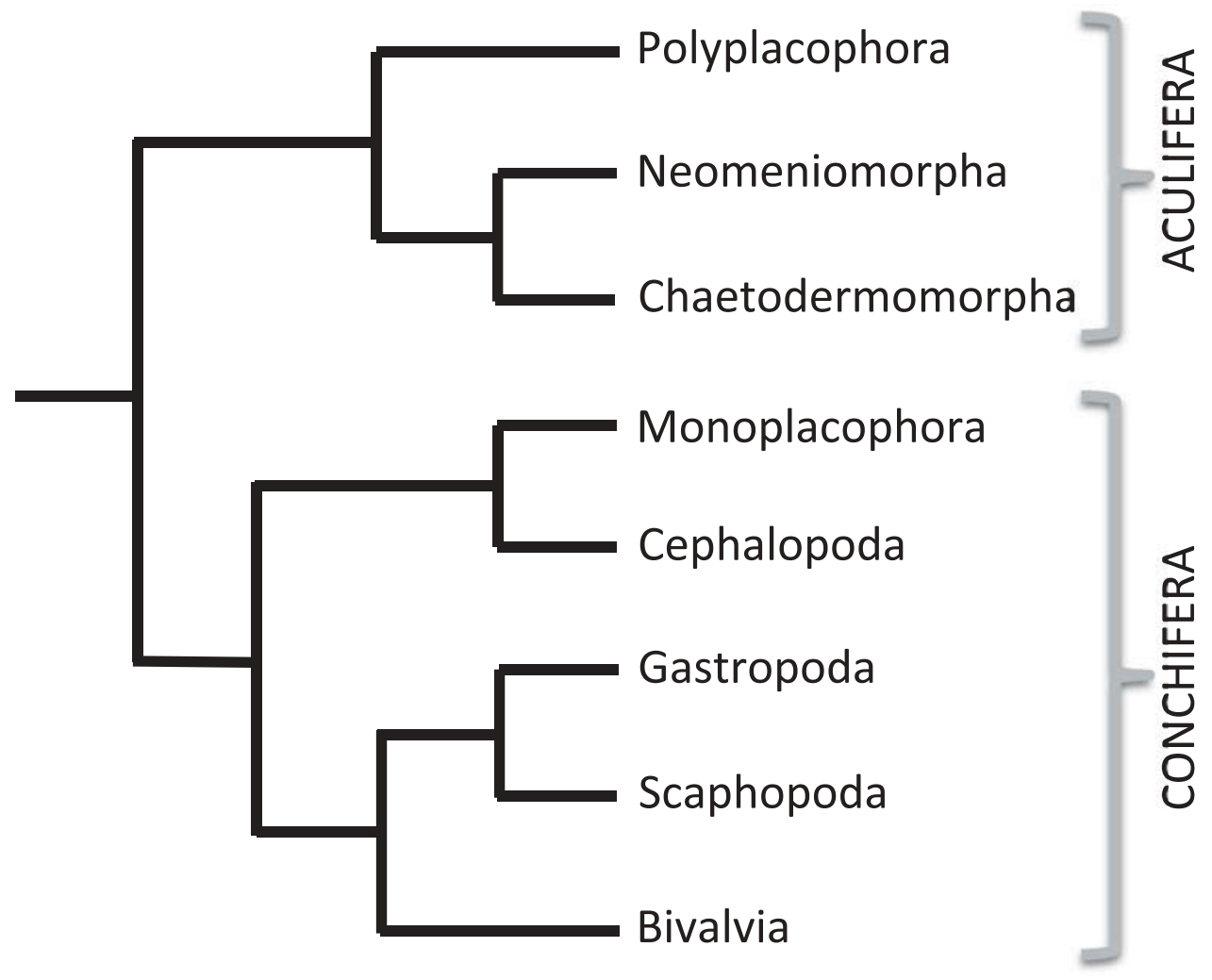

Figure 1. Relationships between molluscan classes as recovered by Smith et al. (2011).

1185 gene regions, totalling 216,402 amino acids. Both studies found support for Aculifera: Solenogastres and Caudofoveata were sister taxa, with Polyplacophora the sister to this clade. Both studies supported Conchifera, although note that Monoplacophora was not included by Kocot et al. (2011). Kocot et al. (2011) recovered a sister-taxon relationship between bivalves and gastropods with scaphopods and then cephalopods as successive sister taxa. Smith et al. (2011) recovered a sister-taxon relationship between gastropods and scaphopods with Bivalvia sister taxon to this clade. Cephalopoda was sister taxon to Monoplacophora (Figure 1).

\section{Cephalopoda: relationships among major lineages}

\section{Early work - mitochondrial studies}

Phylogenetic studies focusing just on cephalopods were first attempted by Bonnaud et al. (1994). They sequenced the 3' end of $16 \mathrm{~S}$ rRNA for 28 cephalopod taxa (27 Decapodiformes and one octopod) and found support for some genera and families (e.g. Ommastrephidae), but no support for higher taxonomic levels. Using partial 16S rRNA sequences of two octopuses (Eledone cirrhosa, Octopus cyanea), two sepiolids (Rossia macrosoma, Sepiola atlantica), an oegopsid (Todarodes sp.), two myopsids (Loligo vulgaris, Sepioteuthis lessoniana) and three sepiids (Sepia officinalis, Sepia 
orbignyana, Sepia latimanus), Boucher-Rodoni and Bonnaud (1996) recovered topologies that supported family groupings, but again did not find support for higher level relationships. They concluded that a more slowly evolving gene was required for examining deep evolutionary relationships. Nonetheless, their results questioned the validity of the order Sepioidea, a taxon which is still not widely accepted.

These same authors published further trees (Bonnaud et al. 1996) based on eight taxa (encompassing an octopod, two loliginids, an oegopsid, Spirula, a sepiolid, a sepiid and Idiosepius), and partial sequences of 16S rRNA and cytochrome oxidase III (COIII). Their 16S rRNA tree again failed to resolve at deeper evolutionary levels, but a tree based on transversion substitutions only of the partial COIII gene did provide some resolution.

Following on from this work, these authors increased the number of taxa in their COIII dataset (Bonnaud et al. 1997). Rooting a neighbour-joining tree based on amino acid sequences with the polyplacophoran Katharina tunicata, they recovered some important groupings. They recovered Octopodiformes, with two octopus species as sister taxa and Vampyroteuthis as successive sister taxon. They recovered Decapodiformes. Here, Idiosepius fell within a clade including two oegopsids (i.e. nonmonophyly of Oegopsida). This clade was sister taxon to a monophyletic Myopsida. Spirula and then a clade comprising two sepiids formed successive sister taxa. In this paper, Bonnaud et al. (1997) also explored GC bias (base composition heterogeneity). They found that the proportion of AT ranged from 72.9 to $58.2 \%$ in COIII, whereas in $16 \mathrm{~S}$ rRNA it ranged only from 71.1 to $73.9 \%$ in the species examined. The species with the highest GC content was Idiosepius pygmaeus. Base compositional, or GC, bias can be a particular problem when resolving the position of taxa like Idiosepiidae (a monogeneric family) that appear to have been evolving independently for some time, because the branches become susceptible to long-branch attraction, and may be attracted to other, distantly related, GC-rich branches. Since the bias appeared to be primarily in the third codon position, amino acid analyses probably limit its effect; however, the issue of GC bias and long-branch attraction is a feature of cephalopod (and indeed some molluscan) phylogenies generally.

The range of genes used in cephalopod phylogenetics continued to expand, and Carlini and Graves (1999) investigated COI as a tool for determining higher-level relationships. Analysing the standard 657-bp (bar-coding) fragment (Folmer et al. 1994), they included a broad spectrum of cephalopod taxa comprising 48 species in total. Recognizing the potential homoplasy in a dataset based on a fast evolving gene, the authors considered various ways to treat their data to minimize the issue. Their topology, based on a weighting system designed to assign less weight to homoplasious characters, recovered both Octopodiformes (Vampyromorpha and Octopoda) and Decapodiformes (all other extant coleoid taxa). However, the study failed to provide resolution at family and order levels. The authors also considered the difficulties of outgroup choice in cephalopod phylogenetics. Although it is now known which of the other mollusc classes is most closely related to cephalopods (see Figure 1), this information was not available at that time. The authors rooted on Katharina sp. (a chiton) and Nautilus pompilius. They discussed the issues of using distant outgroups that are highly divergent. We know with reasonable certainty now that Polyplacophora is in the Subphylum Aculifera. The problem with Nautilus of course, is that it is itself on a long branch, and therefore its sequence is probably highly diverged from that of any common ancestor, and as such it is far from ideal as an outgroup taxon. However, there are 
problems with a lack of alternatives. The authors of this study also included analyses of Decapodiformes and Octopodiformes separately, rooting both on Vampyromorphida, in an attempt to use a less distant taxon. Neither tree resolved satisfactorily, with the Octopodiformes tree particularly divergent from our current understanding. This may in part also reflect the use of a "long-branch" taxon as the outgroup, although again there was a lack of suitable alternatives. However, COI alone is unlikely to provide systematic resolution. The third codon positions are almost certainly saturated, and there is probably insufficient signal in the first and second codon positions, although these might contribute resolving power to an analysis involving additional genes. Additionally, the evolution of a single mitochondrial gene may not reflect the evolution of the taxa as a whole.

\section{Combined mitochondrial analyses}

Other attempts to resolve coleoid relationships with mitochondrial genes include Zheng et al. (2004), Takumiya et al. (2005) and Bonnaud et al. (2005). The first two studies focused on species that were locally available (China and Japan, respectively) but cover a broad range of cephalopod taxa. In the first study, which used both COI and 16S rRNA, six of the 13 included species were sepiids. Neighbourjoining and maximum parsimony analyses were conducted on each gene separately, with COI analysis based both on nucleotide and amino acid sequences. All analyses confirmed the monophyly of Sepiida and Decapodiformes but relationships among other groups were not consistently resolved. The second study included a greater number of taxa and considered three mitochondrial genes: 16S rRNA, 12S rRNA and COI, which were concatenated into a single dataset (with COI as nucleotide rather than amino acid data). The authors separately analysed datasets comprising 17 octopods and 19 decapodiforms, using neighbour-joining, maximum parsimony and maximum likelihood methods with some weighting of tranversions over transitions. They consistently recovered a monophyletic Sepiida and a monophyletic Sepiolidae. However the position of Sepiadarium relative to Sepiolidae varied, and Sepiolida (= Sepiolidae + Sepiadariidae) was not always recovered as monophyletic. Myopsida was consistently recovered as monophyletic but Oegopsida was not. The failure to resolve groups such as Oegopsida that are well established on morphological grounds illustrates the problems with using a small selection of relatively rapidly evolving mitochondrial genes on such a broad spectrum of taxa. All their analyses recovered a monophyletic Octopodidae, but they included only one octopod taxon (Argonauta argo) that was not an octopodid.

Bonnaud et al. (2005) targeted a specific question: the position of Idiosepiida. Building phylogenetic trees using neighbour-joining distance methods, they found that the phylogenetic placement of this taxon varied depending on the genes targeted. A phylogeny based on $16 \mathrm{~S}$ rRNA nucleotide data placed Idiosepius sister to a clade containing Myopsida and Oegopsida. A phylogeny based on 12S rRNA nucleotide data placed Idiosepius sister to a clade containing Sepiolidae and Myopsida; no oegopsids were included in this analysis. A phylogeny based on combined COI and COIII sequences translated to amino acids placed Idiosepius as sister taxon to Oegopsida. The phylogenetic position of Idiosepiida remains unresolved today. 


\section{The introduction of nuclear genes and early combined nuclear and mitochondrial studies}

In an attempt to circumvent the problems with rapidly evolving genes and saturation, Carlini et al. (2000) sequenced a 784-bp fragment of the reportedly very conserved actin gene. They found three actin isoforms (I, II and III). Their maximum parsimony and maximum likelihood trees based on Actin I supported monophyly of Octopodiformes and Decapodiformes. Within Octopodiformes, the internal topology they obtained is not divergent from current thinking (e.g. Strugnell et al. 2013). Within Decapodiformes, monophyly of Bathyteuthida, Sepiolidae, Sepiida, Myposida and Oegopsida was supported, although the relationships among these taxa were not resolved. Nonetheless, this work represented a major step forward and made it clear that more slowly evolving genes held potential for resolving cephalopod phylogenetics.

The search for more slowly evolving genes continued with Bonnaud et al. (2002) exploring the possibilities provided by the nuclear genes $18 \mathrm{~S}$ rRNA and 28S rRNA, which are approximately $1800 \mathrm{bp}$ and $4800 \mathrm{bp}$ long, respectively. Multiple copies of these transcription units occur, but due to "concerted evolution" (Dover 1982), the copies normally remain almost identical within an individual. Warnke et al. (2001) recovered a monophyletic Decapodiformes and Octopodiformes from neighbourjoining and maximum parsimony analyses using $18 \mathrm{~S}$ rRNA, suggesting that this gene might have utility in cephalopod phylogenetics. Bonnaud et al. (2002) however, found that there were highly variable copies of $18 \mathrm{~S}$ rRNA in some cephalopod species. By cloning polymerase chain reaction products before sequencing, they identified two to four copies in five species of cephalopod (Euprymna sp., Spirula spirula, Sepia officinalis, Idiosepius pygmaeus and Vampyroteuthis infernalis). The greatest number of clones (four) was found in Vampyroteuthis. Very high sequence divergence ( $>25 \%$ ) was found between different clones of Spirula spirula, Sepia officinalis and Vampyroteuthis infernalis. At least two clones were sequenced from each polymerase chain reaction amplification (13 species, including octopods, oegopsids and loliginids as well as those taxa already mentioned), but this was insufficient to suggest that multiple copies were not present where they were not found. Because, for some species, they found less similarity between two copies of $18 \mathrm{~S}$ rRNA from a single species, than between sequences from different species, they concluded that great care needed to be taken when using 18S rRNA for cephalopod phylogenetics to ensure that non-homologous forms of 18S rRNA were not included in analyses. They further suggested that nonmonophyly of Mollusca in analyses based on 18S rRNA might be explained by these non-homologous forms, and indeed paraphyly/polyphyly of Mollusca has been found in many studies of metazoan phylogeny based on 18S rRNA (e.g. Winnepenninckx et al. 1996; Mallatt et al. 2010, 2012) although the latter authors preferred to attribute the problems to GC bias and long-branch attraction. Bonnaud et al. (2002) did not detect multiple copies of the 28S rRNA gene, although they acknowledged that this did not preclude their existence and commented that, given that this gene occurs in a cluster with $18 \mathrm{~S}$ rRNA, different forms are a distinct possibility. They also suggested that the phylogenetic signal in the D2 region of $28 \mathrm{~S}$ rRNA might be suitable for resolving relationships within Decapodiformes.

Warnke et al. (2003) used the 18S rRNA gene in an attempt to establish the phylogenetic position of Spirula. They found a maximum likelihood tree based on an ingroup of eight cephalopod taxa, and rooted on a gastropod and a chiton, was almost completely unresolved (i.e. with a basal polytomy). They favoured a 
topology produced by maximum parsimony that placed Spirula as sister to all other Decapodiformes. However they urged caution in accepting this result given that alternative topologies were also recovered in their analyses. The position of Spirula remains unresolved. Difficulties of obtaining tissue mean that Spirula has not been included in a large number of studies.

\section{Large-scale combined analyses}

Lindgren et al. (2004) introduced the use of the nuclear histone H3 gene into cephalopod molecular phylogenetics in a combined study that also incorporated mitochondrial COI and the additional nuclear genes 18S rRNA and partial 28S rRNA, as well as morphological data. Histone $\mathrm{H} 3$ had previously been used in phylogenetic studies of molluscs (Colgan et al. 2000), sipunculids (Maxmen et al. 2003), annelids (Colgan et al. 2001) and was subsequently used in a wide variety of taxa. However, it evolves relatively quickly and the third codon position may be homoplasious when used across multiple phyla (Colgan et al. 2008). This multi-gene dataset (18S rRNA, 28S rRNA, H3 and COI) was analysed under parsimony using the direct optimization method (Wheeler 1996) in POY (Wheeler et al. 2002), both as individual genes and as a concatenated dataset of all genes as nucleotide data. As might be expected from the evolutionary rates of the genes, the COI dataset and the $\mathrm{H} 3$ dataset provided limited resolution at deeper levels when analysed separately, although they provided some useful resolution at termini. An 18S rRNA and 28S rRNA combined dataset found support for Nautiloidea, Coleoidea and Octopoda. Analysis of the combined dataset of all four genes also found support for Nautiloidea and Coleoidea. Additionally, it supported a monophyletic Decapodiformes, but support for Octopoda was lost. This study used the most comprehensive set of outgroup taxa to date. The authors included 18 outgroup taxa drawn from other molluscan classes and including a caudfoveate, two solenogasters, four chitons, four gastropods, four bivalves and three scaphopods. The study also contained a cladistic analysis of a morphological dataset and an analysis of that dataset combined with the molecular dataset.

Strugnell et al. (2004) introduced three additional nuclear genes (pax6, rhodopsin and octopodine dehydrogenase) to cephalopod molecular phylogenetics, designing cephalopod-specific primers from available invertebrate sequences. They used these in combination with three mitochondrial genes in maximum likelihood and Bayesian inference analyses. They found that the ctenoglossans (families Vitreledonellidae and Bolitaenidae) fell within a clade containing members of the family Octopodidae, suggesting that Octopodidae was not monophyletic. They further suggested that the ctenoglossans might have neotenous origins. Sister to the well-supported clade containing Octopodidae and the ctenoglossans was Argonautoidea, and the successive sister taxon was Cirrata.

Strugnell et al. (2005) built on this study by including more decapodiform taxa and analysing their data using Bayesian inference either as a combined six-gene dataset, a combined nuclear (three-gene) dataset, or a combined mitochondrial (three-gene) dataset. Furthermore, the datasets were partitioned either by gene, by codon position, or both. They analysed Octopodiformes separately, Decapodiformes separately and then combined all taxa. They treated significant base frequency heterogeneity by RY coding (whereby all purines, A and G, are coded as Rs, and all pyrimidines, $\mathrm{T}$ and $\mathrm{C}$, are coded as $\mathrm{Ys}$ ) the third codon positions. Interestingly, they found 
multiple copies of octopine dehydrogenase $(\mathrm{ODH})$ in two oegopsid species. These varied by between 3 and 12\%. Because of the large number of analyses (based on the models specified above), they used the Akaike Information criterion to find the optimal model for the nine datasets: (Octopodiformes/Decapodiformes/All taxa) $\times$ (six genes/three nuclear genes/three mitochondrial genes). The Akaike Information criterion-selected model for analyses involving all six genes and the three nuclear genes consistently recovered accepted groupings (e.g. Myposida, Oegopsida, Sepiida, Sepiolidae, Cirrata, Argonautoidea, Octopodinae) as monophyletic, and also recovered a sister-taxon relationship between Sepiidae and Spirula. However, analyses involving just the mitochondrial genes did not always recover all of these groups as monophyletic. Octopodidae sensu Sweeney and Roper (1998) was never recovered as monophyletic (see later). These analyses provided some resolution as to the relationships between orders, suborders and families within Octopodiformes but still did not provide resolution within Decapodiformes.

The growing interest in cephalopod phylogenetics, more effective sequencing methodologies and the proliferation of alignment and analysis methods, led Strugnell and Nishiguchi (2007) and Lindgren and Daly (2007) to investigate what differences in topologies might result from different methodologies applied to the same dataset. Strugnell and Nishiguchi (2007) compiled a multigene dataset of previously published sequences (comprising six nuclear genes: 18SrRNA, 28s rRNA, histone H3, ODH, rhodopsin, pax6; and three mitochondrial genes: 12S rRNA, 16s rRNA and COI). They prepared two alignments of the concatenated dataset: one by eye, and one using the direct optimization method of Wheeler (1996) implemented in POY (Wheeler et al. 2002). They also RY encoded regions of their "by eye" alignment where chi-squared tests detected base frequency heterogeneity (third codon positions of COI, ODH and rhodopsin) to give a third alignment. They then analysed these three alignments using parsimony, maximum likelihood and Bayesian inference. Unsurprisingly, tree topology was affected both by alignment methodology and tree-building methodology. However, since there are so many unknowns in cephalopod evolution it is not possible to indicate which methods are "better". Nonetheless, some interesting points can be drawn from the conclusions.

There is strong morphological and embryological evidence (e.g. Young and Vecchione 1999) that Vampyromorphida is an octopodiform, but only the maximum likelihood and Bayesian inference analyses of RY-coded data supported this relationship. Possibly this relationship is obscured in other analyses by either base frequency heterogeneity or saturation. RY coding should rectify base frequency heterogeneity and reduce saturation because nucleotides $(\mathrm{A}, \mathrm{T}, \mathrm{C}, \mathrm{G})$ are converted into purines and pyrimidines to attempt to normalize relative base frequencies across a tree topology (e.g. Lindgren et al. 2012). Parsimony may perform more poorly under high rates of evolutionary change (Huelsenbeck and Hillis 1993). If RY coding cannot completely rectify the saturation, this may account for parsimony analysis not recovering this relationship. Certainly there is a strong case to treat data for base frequency heterogeneity and saturation. In this study, Oegopsida was consistently found to be monophyletic. Other studies had found polyphyly, with either Spirula (Carlini and Graves 1999; Carlini et al. 2000; Lindgren et al. 2004), Myposida (Takumiya et al. 2005) or Idiosepius (Bonnaud et al. 1997) falling within the oegopsid clade. Strugnell and Nishiguchi (2007) also recovered a sister-taxon relationship between Oegopsida and Bathyteuthida in all nine trees, supporting previous molecular (Carlini et al. 2000; 
Strugnell et al. 2005) and morphological (Naef 1921/1923) studies. The placement of other decapodiforms was highly variable and dependent on the alignment/analysis method.

Lindgren and Daly (2007) made a similar exploration of factors affecting tree topologies, with a more direct assessment of the impact of highly variable regions. Using 18S rRNA and focusing on decapodiform taxa, they compiled three datasets of 41 taxa (plus Vampyroteuthis as an outgroup). The first dataset contained only the conserved portions of $18 \mathrm{~S}$ rRNA, the second only the variable portions, and the third contained the whole sequence. They applied two alignment methods to each dataset: the direct optimization of Wheeler (1996) implemented in POY (Wheeler et al. 2002) and a more traditional multiple sequence alignment implemented in ClustalX. In addition, they implemented each alignment three times, changing the weighting of parameters of each run. In ClustalX, the default "cost" (which they also implemented) of different substitutions/indels (opening gap : transition : transversion : extension gap) is $15.5: 1: 1: 6.66$. These parameters were implemented in POY and ClustalX as initially all equal (i.e. $1: 1: 1: 1$ ) but the cost of opening a gap was doubled on the second implementation $(2: 1: 1: 1)$ and again on the third $(4: 1: 1: 1)$. Hence there were 21 alignments in total (ClustalX default, plus three differently weighted implementations in ClustalX and three differently weighted implementations in POY). Parsimony analysis, implemented in TNT (Goloboff et al. 2004), was then used to generate tree topologies for each alignment. The authors then used incongruence length differences between the topologies as a metric to evaluate which parameters produced the best combined dataset. They then examined the trees produced by the conserved, variable and combined datasets for these parameters. They concluded that alignment software had a greater effect on topology than gap or substitution costs, and that the variable regions of the alignment contained a great deal of phylogenetic signal, possibly because variable regions contain segments that are conserved among closely related taxa. In contrast, the conserved regions were so conserved that they contained very little phylogenetic signal for discriminating within Decapodiformes. Many decapodiform relationships remained unresolved with conflicting topologies. However, this study consistently recovered Spirulida and Sepiida as sister taxa, with Sepiolidae as successive sister taxa, and a sister-taxon relationship between Idiosepiidae and Myopsida. It also recovered family groupings within Oegopsida that will be discussed later. One interesting finding of these analyses was that the default setting in ClustalX produced the most incongruent alignments. One issue with assessing "quality" across alignments is finding a good metric to do so. In this study, the authors used the Incongruence Length Difference test, which has been used as a metric for evaluating levels of disagreement across datasets (e.g. Farris et al. 1995; Wheeler and Hayashi 1998; Aagasen et al. 2005). However, some authors (e.g. Barker and Lutzoni 2002; Darlu and Lecointre 2002; Dowton and Austin 2002) argue that incongruence tests are not suitable for this purpose.

Lindgren (2010) performed an intensive study of the relationships within Oegopsida, but also included other decapodiform taxa to further assess higher-level relationships. The author used five genes (18S rRNA, 28S rRNA, Histone H3, 16S rRNA, COI) and included 72 oegopsids, four bathyteuthids, four myopsids, Idiosepius, Spirula, two sepiids and four sepiolids. Obviously, taxon sampling was biased towards oegopsids, but the resulting topology did recover monophyletic Bathyteuthida, Myopsida, Sepiida and Sepiolidae as well as a monophyletic Oegopsida. The 
bathyteuthids were the sister taxon to Oegopsida. Relationships among other decapodiform higher taxa were not robust and differed between parsimony, likelihood and Bayesian analyses. The problem of a lack of suitable outgroup taxa was again raised, specifically with regard to choosing an appropriate outgroup relative to the genes being studied. The problem lies largely with the nuclear ribosomal genes. 18S rRNA and 28S rRNA are capable of providing information for both higher-level and lower-level relationships but are problematic because their secondary structure contains a large number of loop regions. These variable regions, which have been demonstrated to be phylogenetically important for lower-level relationships (Lindgren and Daly 2007), are extremely difficult to align and establish putative homologies because any "outgroup" is so widely diverged.

Lindgren et al. (2012) analysed a supermatrix dataset of 188 taxa with published sequences (or partial sequences) for four or more of 10 selected genes (18S rRNA, 28S rRNA, Histone H3, pax6, ODH, rhodopsin, COI, cytochrome b, 12S rRNA, 16S rRNA). They used a multiple alignment method implemented in MUSCLE (Edgar 2004) and then assessed which partition model (out of 16 possibilities) was best using the Bayesian Information Criterion. Interestingly, the most heavily partitioned model best fitted the data, although a scheme that partitioned the genes into nuclear, mitochondrial and ribosomal and partitioned the protein coding genes into first/second codons and third codons was also a good fit. The resulting maximum likelihood tree, rooted on a selection of Nautiloidea, found support for monophyly of Sepiida, Myopsida, Sepiolidae, Bathyteuthida and Oegopsida. Bathyteuthida was supported as the sister taxon of Oegopsida. Sepiadariidae was supported as sister taxon to Sepiolidae, providing molecular support for Sepiolida (= Sepiolidae + Sepiadariidae). Decapodiformes received high bootstrap support but no other relationships within the clade were resolved. This analysis also supported a monophyletic Octopodiformes with Vampyroteuthis as sister to Octopoda. Octopodidae was polyphyletic, as noted in previous studies (Carlini et al. 2001; Strugnell et al. 2004).

Interestingly, the most recent papers (Lindgren et al. 2012; Strugnell et al. 2013) all map character traits onto phylogenies. This was first attempted by Vecchione et al. (2000) on a phylogeny based on COI. Although outside the scope of this review, such methodologies will probably increase our understanding of the evolution of morphological characters within cephalopods as phylogenies begin to stabilize.

\section{The contribution of whole mitochondrial genomes}

Other studies that are improving our understanding of cephalopod evolution are those that have sequenced entire mitochondrial genomes. The first cephalopod whole mitochondrion sequence available was that of Loligo bleekeri (Sasuga et al. 1999; Tomita et al. 2002). The genome was $17,211 \mathrm{bp}$ long and, while containing the standard set of metazoan mitochondrial genes, it contained several duplicated non-coding regions and had a gene order not found in any other metazoan. Three more cephalopod mitochondrial genomes (Octopus vulgaris, Watasenia scintillans and Todarodes pacificus) were then published (Yokobori et al. 2004). Both oegopsid species had five duplicated genes (COI, cytochrome oxidase II [COII], COIII, ATP synthase subunit 6 [ATP6], ATP synthase subunit 8 [ATP8]) and a duplicated tRNA [Asparagine]) a novel discovery in eukaryotes. The duplicated sequences were either identical, or almost identical, suggesting that concerted evolution mechanisms were in play. 
Akasaki et al. (2006) sequenced another specimen of each of Watasenia scintillans and Todarodes pacificus and three additional species: Sepioteuthis lessoniana, Sepia officinalis and Octopus ocellatus. They confirmed the gene duplications in oegopsids and found extensive rearrangements in Sepioteuthis compared with the closely related Loligo bleekeri. A phylogenetic tree based on maximum likelihood analysis of the amino acid sequences of the 13 protein-coding genes and rooted on Octopus showed the two oegopsids as sister taxa, the two myopsids as sister taxa, and Oegopsida and Myopsida as sister taxa to the exclusion of Sepia.

Boore (2006) sequenced the mitochondrial genome of Nautilus macromphalus, thereby potentially providing an outgroup (albeit one on a long branch) for future phylogenetic studies. Yokobori et al. (2007) added whole mitochondrial sequences from Vampyroteuthis infernalis and Sepia esculenta. The gene order of the Vampyroteuthis genome was, remarkably, given the rearrangements found in Decapodiformes mitochondrial genomes, identical to that of Octopus vulgaris, and possessed relatively few differences in arrangement from the gene order within Nautilus. Yokobori et al. (2007) built a variety of phylogenetic trees based on slightly differing models using parsimony, maximum likelihood and Bayesian inference. Monophyly of Octopodiformes (= Vampyromorpha + Octopoda) was more strongly supported than an alternative topology with Vampyromorpha as sister to Decapodiformes, but this alternative topology could not be rejected by the approximately unbiased test of Shimodaira (2002). Within Decapodiformes, the tree recovered a monophyletic Myopsida as sister to a monophyletic Oegopsida, with a monophyletic Sepiida as successive sister taxon.

Staaf et al. (2010) published four additional whole genome sequences (three from Sthenoteuthis oualaniensis and one from Dosidicus gigas) that were sequenced during a project seeking suitable markers for analysing the population structure of these species in the eastern Pacific. These sequences suggest that the duplication of part of the genome seen in other oegopsids is a feature common to the group.

Allcock et al. (2011a) reanalysed the available whole mitochondrial data in a maximum likelihood framework, adding short sequences of key taxa (Spirulida, Sepiolidae, Sepiadariidae, Idiosepiidae, Bathyteuthida) to some analyses to improve the taxon sampling. The analysis recovered a monophyletic Octopodiformes and monophyletic Decapodiformes. Relationships among Decapodiformes taxa were again not well supported; however, there was some indication that Spirula might be basal, and the topology obtained was not incongruent with morphological hypotheses. Allcock et al. (2011a) also used phylogenetic techniques to analyse the data contained within the order of the mitochondrial genes. These methods have revealed useful phylogenetic signal in other groups such as Arthropoda (Boore et al. 1995). However, either the arrangements in Cephalopoda have been too extensive, or the taxon sampling is not yet sufficient to reveal evolutionary relationships in Cephalopoda, although where these analyses did resolve (rather than producing a basal polytomy) they supported Octopodiformes and Decapodiformes.

More recently, two additional cephalopod whole mitochondrial genomes have been published: Octopus minor (Cheng et al. 2012) and Loligo edulis (Takemoto and Yamashita 2012). The genomes of these newly sequenced species have the same gene composition and gene order as Octopus vulgaris and Loligo bleekeri, respectively.

Although there is an increase in the number of published whole mitochondrial genomes, these taxa are still only drawn from Oegopsida, Myopsida, Sepiida, 
Vampyromorphida, Octopoda and Nautilus. Recent phylogenetic trees based on amino acid sequences including the additional available genome sequences (Cheng et al. 2012) continue to yield a topology that supports Octopodiformes and Decapodiformes (although usually with stronger support for Decapodiformes), and within Decapodiformes supports a sister-taxon relationship between Oegopsida and Myopsida with Sepiida as successive sister taxon.

As well as the published sequences, whole mitochondrial genomes exist on GenBank for several other species including taxa not in Oegopsida, Myopsida, Sepiida or Octopoda. Phylogenetic analyses including these species may improve our understanding of relationships within Decapodiformes.

\section{Genome duplications and genome size}

It is understood that there have been partial mitochondrial genome duplications in cephalopods, for example in the oegopsids. Hallinan and Lindberg (2011) investigated chromosome number across all molluscs and used likelihood models to estimate the placement of whole genome duplication events on a phylogenetic tree. Although cephalopod karyological studies have not been numerous, chromosome numbers have been reported for several species of cephalopod (Table 2). Hallinan and Lindberg suggest that at least one whole genome duplication event took place in Cephalopoda. They estimate that the duplication most probably took place in the coleoid common ancestor, after it diverged from Nautiloidea, but before Decapodiformes diverged from Octopodiformes. However, their data also provide some evidence that the duplication event may have occurred in the Decapodiformes lineage after it split from Octopodiformes but before divergence of the sepiid and myopsid branches. Furthermore, there is weak support for multiple whole genome duplications. They suggest that, based simply on chromosome counts, other scenarios are also possible.

In fact, Bonnaud et al. (2004) had already considered this question in cephalopods. While providing karyological information for Nautilus macromphalus, Bonnaud et al. (2004) also mapped chromosome number onto a consensus tree constructed from 16S rRNA data and morphological data (Figure 2). Bonnaud et al. (2004) considered Nautilus to be the ancestral karyotype and suggested a polyploidy event early in the Decapodiformes lineage (Figure 2) in line with one of the scenarios suggested by Hallinan and Lindberg (2011). Re-consideration of this issue with an ancestral karyotype of $n=15$ (Hallinan and Lindberg 2011) might be suggestive of more than one duplication event, although newly published karyotypes for additional cuttlefish species (Papan et al. 2010; Jazayeri et al. 2011) substantially reduce the lower boundary for chromosome number in Sepiida (Table 2). Additional karyological data, particularly of oegopsid, spirulid and idiosepiid species, might improve our understanding of cephalopod evolution, the number of duplication events and the nature of these.

Some information has been gathered on cephalopod genome size (Albertin et al. 2012), which may also give an indication of duplication events. Cephalopod genomes appear to be large in comparison with many other metazoan genomes and also rich in repeated regions (Yoshida et al. 2011; Albertin et al. 2012). Size may not be directly related to whole genome duplication events, as the increase can also be the result of lineage-specific increases in smaller repeat elements (Yoshida et al. 2011), but the general large size (2.1-4.5 Gb; Albertin et al. 2012) may be indicative of duplication in stem lineages. Yoshida et al. (2011) analysed the genomes of a pygmy squid (Idiosepius 
A.L. Allcock et al.

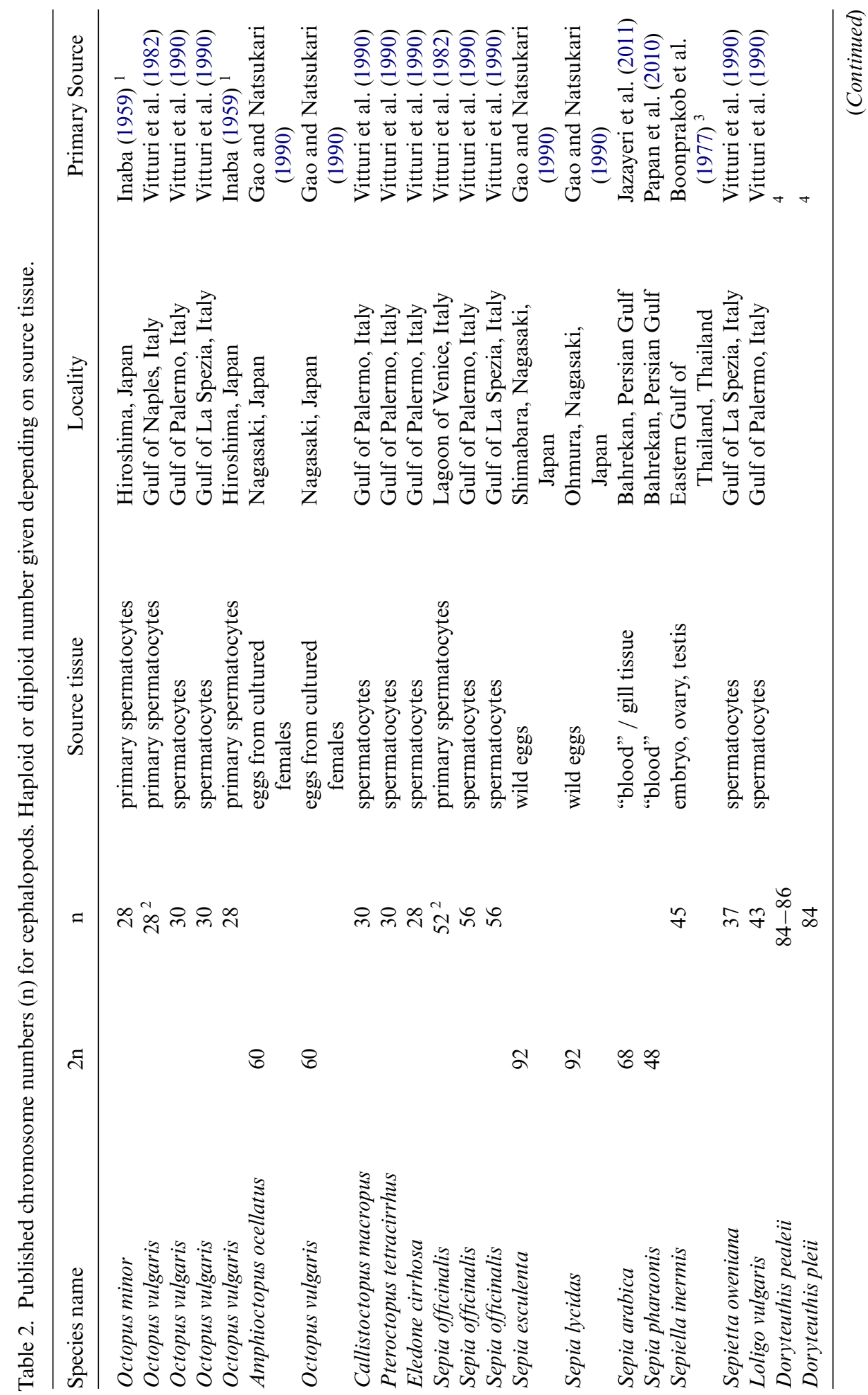




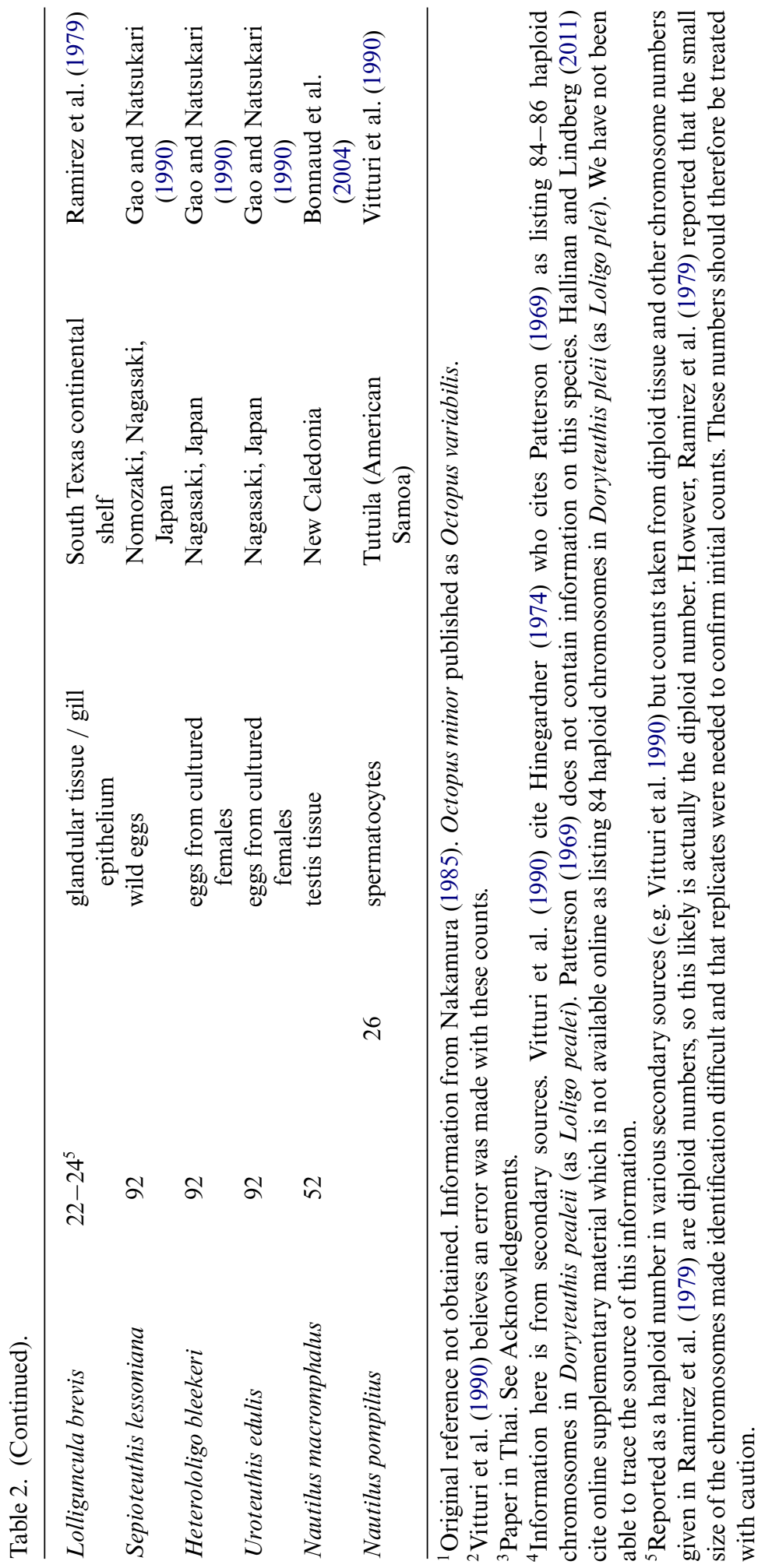




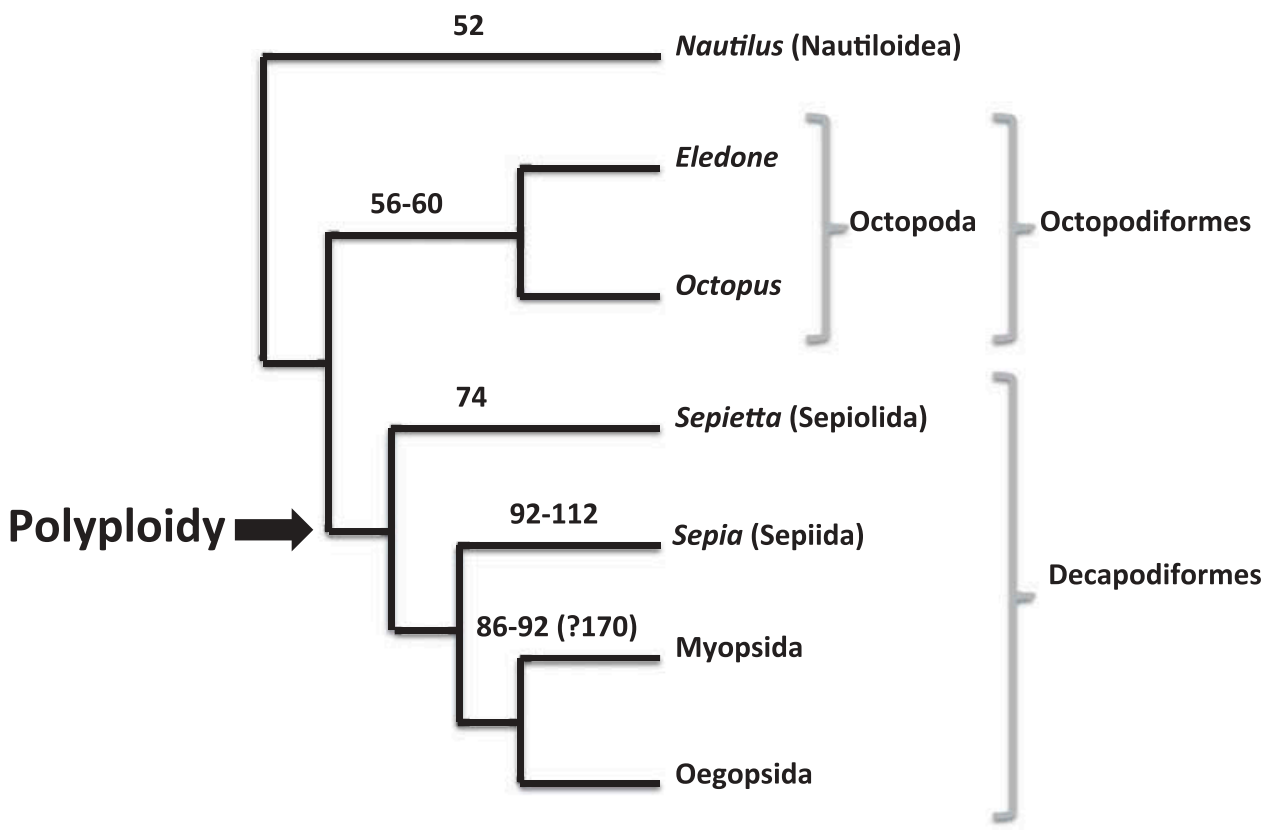

Figure 2. Polyploidy scenario suggested by and reproduced from Bonnaud et al. (2004). Updated diploid chromosome numbers (see Table 2) for the various branches are now Nautiloidea 52; Octopoda 56-60; Sepiolida 74; Sepiida 48-112; Myopsida 86-92 (?22-?172).

paradoxus), a nautilus (Nautilus pompilius) and a scallop (Mizuhopecten yessonensis). They identified all protein-coding genes that had at least one homologue, estimated the ages of the gene duplications and concluded that a single duplication event occurred in the cephalopod lineage, affecting both Idiosepius and Nautilus.

The move towards cephalopod genomics will likely contribute enormously towards our understanding of cephalopod evolution, even though the reasons that particular taxa are targeted are likely to vary widely (e.g. Albertin et al. 2012). Genomic approaches solved major evolutionary conundrums in Mollusca as a whole, but several efforts to obtain funding for a similar approach in Cephalopoda have not been successful. Although the cephalopod tree is not yet fully resolved, our understanding has improved considerably through targeted sequencing of short gene regions. We present a tree (Figure 3) that summarizes current knowledge of higher taxonomy.

\section{Estimating divergence times}

Molecular phylogenies have been used in conjunction with biogeographical and fossil time constraints to estimate divergence times of cephalopod clades. Lieb and Markl (2004) used a fossil calibration point of 520 million years ago (Ma), representing the gastropod-cephalopod split, to estimate divergence times of four molluscan lineages (Vetigastropoda, Opisthobranchia, Protobranchia and Cephalopoda; including Nautilus, Octopus and Sepia) on a phylogeny built using haemocyanin sequences. They estimated that coleoid and nautiloid lineages diverged $\sim 420 \mathrm{Ma}$ and decapodiform and octopodiform lineages diverged $\sim 220 \mathrm{Ma}$. 


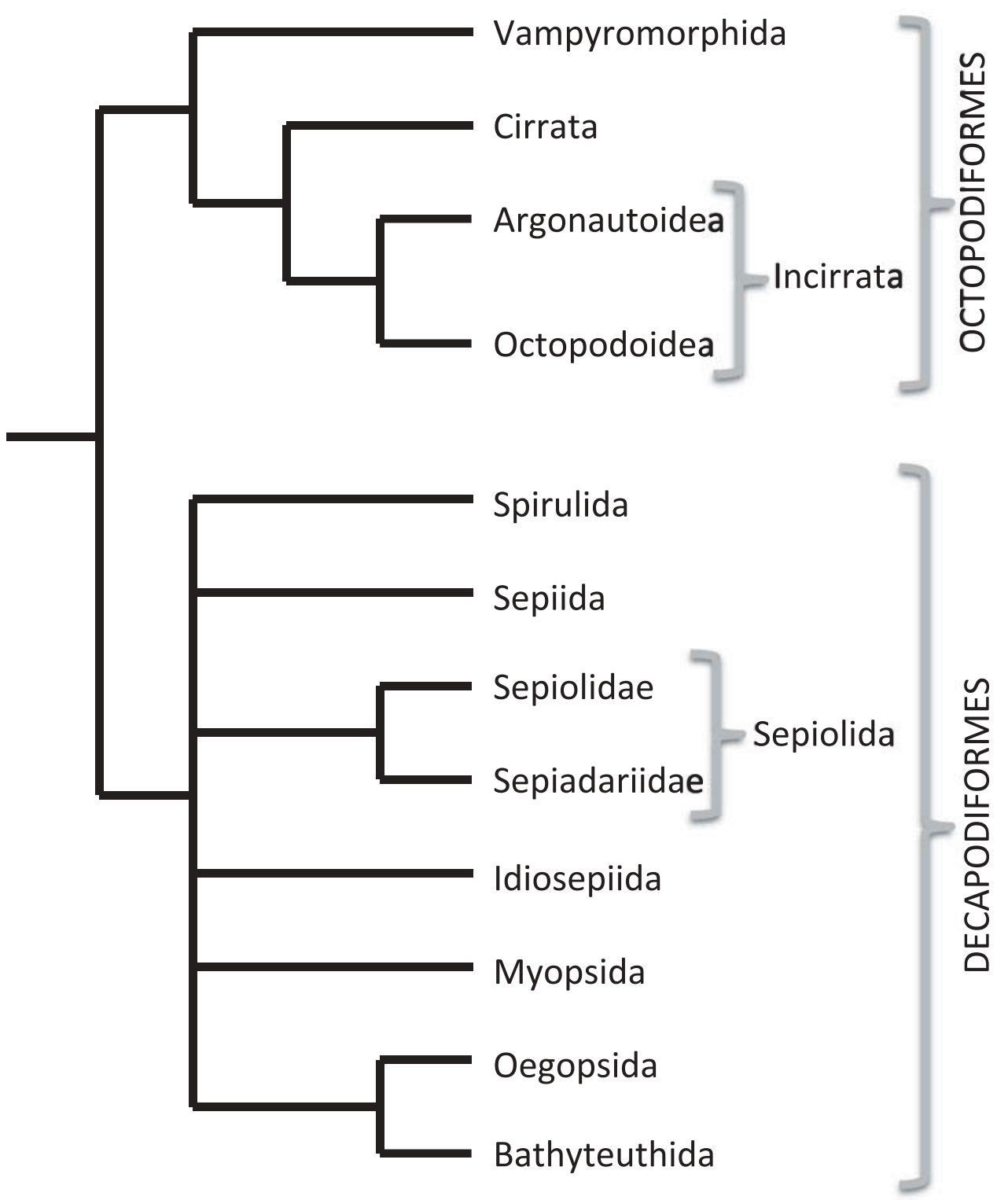

Figure 3. Summary tree of phylogenetic relationships between higher taxa.

Strugnell et al. (2004) used penalized likelihood methods (incorporating time constraints from the fossil record) to estimate the divergence time of the ctenoglossan lineage on a phylogeny built using six genes (rhodopsin, ODH, pax-6, COI, 12S rRNA and 16S rRNA). They estimated that the ctenoglossan lineage diverged from other octopods 48 Ma. Subsequently, Strugnell et al. (2006a) used the same genes in datasets from their earlier work (Strugnell et al. 2005) to estimate divergence times of the major cephalopod clades. Bayesian analyses suggested a much earlier origin for 
the major lineages than previous studies had suggested based on the fossil record alone. These included a Palaeozoic origin of the orders Vampyromorpha, Octopoda and the majority of the extant higher-level decapodiform taxa. This is likely to be related to the fossils used as constraint points within the analysis. At that time, the authors could find only nine suitable fossil constraints, two of which were of contentious classification. The authors completed their analyses both with and without these contentious fossils, the results showing a notable extension of the mean age of divergence of the main nodes when these fossils were included. A subsequent study focusing on the octopodiforms (Strugnell et al. 2008a) used the same six genes, but also COIII on a dataset containing 34 octopodiforms. This resulted in similar divergence time estimates within Octopoda as previous studies.

Recent work has revealed many more cephalopod fossils that pertain to extant lineages such as Octopoda (e.g. Fuchs et al. 2009) and reanalysis may yield younger origins of these lineages. Warnke et al. (2011) estimated the mean date of divergence of Spirulida from Sepiida based on differences in haemocyanin sequences, since a molecular clock for this gene has been calibrated in molluscs. Warnke et al.'s estimate of $150 \mathrm{Ma}$ was younger than that of Strugnell et al. (2006a) who obtained a mean date between 206 and $313 \mathrm{Ma}$ for this divergence (varying by genes/fossils included in the analysis). Kröger et al. (2011) produced Bayesian estimates of divergence times between Nautiloidea/Coleoidea, between Decapodiformes/Octopodiformes, between Idiosepius/Euprymna and between Octopus/Enteroctopus. Mean dates for these divergences were 416, 276, 140 and $153 \mathrm{Ma}$, respectively. The Idiosepius/Euprymna estimate is considerably younger than that found by Strugnell et al. (2006a) while the Octopus/Enteroctopus estimate is considerably older. This is probably an area to which a substantial amount of effort will be devoted in the future given the rapid improvement in cephalopod phylogenies, the removal (or at least lessening) of computing power constraints, and the discovery and description of new pertinent fossils. In addition, the continued resolution of cephalopod phylogenies will in turn aid interpretation of coleoid cephalopod fossils and may allow more coleoid fossils to be useful for divergence-time analyses.

\section{Cephalopoda: relationships within major lineages}

\section{Octopoda}

\section{Cirrata}

As discussed above, Octopoda and Vampyromorphida are sister orders within Octopodiformes. Within Octopoda, the suborder Cirrata forms a sister clade to all other octopods (Carlini et al. 2000; Strugnell et al. 2004, 2005, 2013; Lindgren et al. 2012) (Figure 3). There have been few studies examining molecular phylogenetic relationships among cirrates. A molecular study using 16S rRNA suggested that there are four cirrate families (Piertney et al. 2003) and the taxonomy has been revised to reflect that (Collins and Villanueva 2006). The 16S rRNA phylogeny placed Grimpoteuthidae and Opisthoteuthidae as sister taxa. Cirroctopodidae was sister taxon to the Grimpoteuthidae/Opisthoteuthidae clade, and Cirroteuthidae was sister taxon to the other three cirrate families. This arrangement has some congruence with morphology: Cirroteuthidae differs from the three other families by its complex secondary web (Collins and Villanueva 2006). The three other families are united 
by their gill form, which is described as "half-orange" (Collins and Villanueva 2006) as opposed to "sepioid" in Cirroteuthidae. However, evolution of these characters is not sufficiently understood to determine whether this is a synapomorphy. Molecular sequence data have been used to confirm the identity of various cirrate species (e.g. Cuccu et al. 2009; Collins et al. 2010) and there is certainly scope for further molecular studies on this taxonomically difficult group.

\section{Incirrata}

The superfamily Argonautoidea appears to be the sister group to all other incirrate octopods (Strugnell et al. 2004, 2013; Lindgren et al. 2012) (Figure 3). Strugnell and Allcock (2010) sequenced four mitochondrial genes to investigate the relationships between the four families comprising Argonautoidea and to estimate divergence times of the families. The resulting molecular tree recovered a sister-taxon relationship between Alloposidae and Tremoctopodidae and between Argonautidae and Ocythoidae in support of the relationships proposed by Naef $(1921 / 1923)$ and Bizikov (2004) based on morphological synapomorphies.

All other incirrate octopods consistently form a well-supported clade, superfamily Octopodoidea, in molecular phylogenies, but certain families within this clade fail to resolve (Strugnell et al. 2004, 2005, 2013; Lindgren et al. 2012) (Figure 3). That Octopodidae (sensu Sweeney and Roper 1998) might not be monophyletic was suggested early in the history of cephalopod molecular phylogenies (Carlini and Graves 1999; Carlini et al. 2001) but the COI trees on which this suggestion was based also failed to resolve groups for which there are really strong morphological synapomorphies so further evidence was required. It was provided by Strugnell et al. (2004) with a robust phylogeny built from three nuclear and three mitochondrial genes. This clearly placed the genera Vitreledonella, Bolitaena and Japetella as sister to some (but not all) octopodid taxa. These three genera, which were traditionally divided between two families (Vitreledonellidae and Bolitaenidae), had previously been united in a separate suborder, Ctenoglossa, on the basis of their distinctive toothcomb radula (Naef 1921/1923; Robson 1932). Their apparent placement within Octopodidae has since been supported by other studies (Strugnell et al. 2008a, 2013, Lindgren et al. 2012), which has led to Strugnell et al. (2013) proposing a revised taxonomy (see below) for the groups involved.

Several well-supported groupings have been recovered in a number of studies. The genus Eledone generally has not grouped closely with any other included genera except Aphrodoctopus (Strugnell et al. 2013) and may be a long branch (e.g. Lindgren et al. 2012).

Bathypolypus similarly fails to group closely with other genera (Carlini et al. 2001; Guerra et al. 2010; Lindgren et al. 2012) and may also be on a long branch (Guerra et al. 2010; Strugnell et al. 2013).

The genera Muusoctopus (formerly Benthoctopus) and Enteroctopus generally form a clade (e.g. Strugnell et al. 2004, 2005, 2006a, 2011, 2013; Lindgren et al. 2012) and, when included, Vulcanoctopus and Sasakiopus are closely related to these genera (e.g. Strugnell et al. 2009a; Jorgensen et al. 2010). Before molecular work, Enteroctopus had always been aligned in the subfamily Octopodinae with, among others, the genus Octopus. However, numerous studies have shown that Octopus and Enteroctopus are not closely related (e.g. Barriga-Sosa et al.1995; Takumiya et al. 2005; Kaneko et al. 
2011; Lindgren et al. 2012; Toussaint et al. 2012). Despite suggestions to the contrary (e.g. Norman et al. 1997; Gleadall 2004) and although the type of Muusoctopus (Muusoctopus januarii) has still not been sequenced, molecular evidence to date suggests that Muusoctopus is monophyletic (e.g. Allcock et al. 2006; Strugnell et al. 2009a, 2011; Vecchione et al. 2009).

All benthic incirrate genera with uniserial suckers and non-heteromorphic arm tips (i.e. excluding Eledone and Aphrodoctopus) consistently group together (Carlini et al. 2001; Strugnell et al. 2004, 2005, 2008a, 2013; Guerra et al. 2010; Lindgren et al. 2012). These genera tend to be found in the Southern Ocean or deep sea and it has been shown that their evolutionary origins were in the Southern Ocean and that as cold deep water spread northwards with the development and intensification of the thermohaline circulation, this facilitated the evolutionary radiation of this clade (Strugnell et al. 2008a). There has also been extensive molecular work supporting morphological systematics of this group and investigating biogeographical aspects (e.g. Allcock and Piertney 2002; Allcock et al. 2007, 2008, 2011b; Strugnell et al. 2008b, 2012).

These Antarctic and deep-sea octopods often form a sister clade to a monophyletic group containing the pelagic incirrate octopods in the families Amphitretidae, Vitreledonellidae and Bolitaenidae (Strugnell et al. 2004, 2005, 2006a; Lindgren et al. 2012) although alternative topologies have been recovered (Strugnell et al. 2013). This phylogenetic placement within the benthic octopods led Strugnell et al. (2004) to propose that the ctenoglossans had evolved by neotony, although their close association with benthic species that lack a larval stage suggests that very different evolutionary pressures have affected the two groups.

The remaining genera were traditionally considered to belong to the subfamily Octopodinae. However, given the many taxonomic problems outlined above, Strugnell et al. (2013) proposed a revised taxonomy (Figure 4) whereby they raised this subfamily to family status as Octopodidae sensu Strugnell et al. 2013. Although many studies have included species from this group, only a few have targeted good taxon coverage to understand relationships within it. These studies have uncovered consistent relationships (Figure 5). Amphioctopus and Hapalochlaena are usually recovered as sister taxa (Guzik et al. 2005; Kaneko et al. 2011; Lindgren et al. 2012; Strugnell et al. 2013) with Octopus sensu stricto (= species closely related to Octopus vulgaris) forming a close relationship with these genera (Guzik et al. 2005; Takumiya et al. 2005; Lindgren et al. 2012; Strugnell et al. 2013). Where included, Ameloctopus and Cistopus are sister taxa (Guzik et al. 2005; Strugnell et al. 2013). Kaneko et al. (2011) recovered a well-supported clade including Abdopus, Cistopus, Octopus s.s., Amphioctopus and Hapalochlaena using just two mitochondrial genes. A similar clade (but also including Ameloctopus, which was not sequenced by Kaneko et al. 2011), was highly supported in the analyses of Strugnell et al. (2013) (Figure 5D). Octopus (s.1.) rubesens also shows some affinity with this group (Lindgren et al. 2012; Figure 5C). Scaeurgus, Macroctopus, Callistoctopus and Grimpella have been recovered as a clade (Strugnell et al. 2013) and there is evidence that the "Octopus australis group" may be associated with these genera because of its close association with Callistoctopus (Lindgren et al. 2012). Several genera (e.g. Thaumoctopus, Wunderpus, Euaxoctopus) are yet to be included in such studies and the placement of many species referred to Octopus sensu latissimo is unknown. A recent attempt was made to place Octopus tehuelchus using COIII (Acosta-Jofré et al. 2012). It was clear from this single gene that Octopus tehuelchus does not belong in Octopus sensu stricto and is most likely allied with 


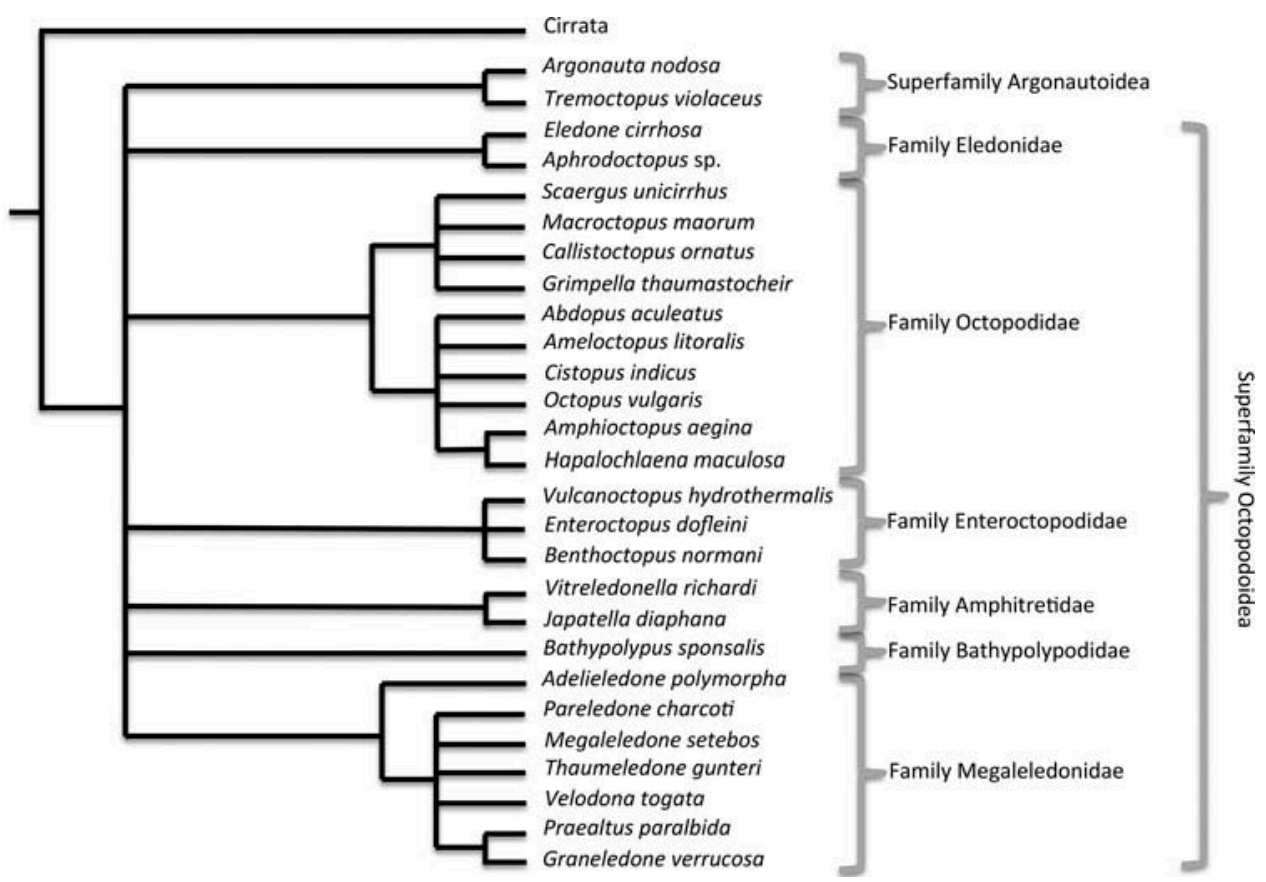

Figure 4. Consensus tree depicting phylogenetic relationships supported by all analyses conducted by Strugnell et al. (2013).

the Scaeurgus/Macroctopus/Callistoctopus/Grimpella clade. Future molecular work involving multiple genes will probably solve the placement of many genera and species, while DNA barcoding (i.e. COI sequencing) is likely to help recover clades of closely related species within Octopus s.l. COI appears to be particularly useful at this level: it clearly discriminates closely related species of Amphioctopus (Kaneko et al. 2008, 2011; Dai et al. 2012), Callistoctopus (Kaneko et al. 2008, 2011), Cistopus (Zheng et al. 2012a) and may be useful for detecting cryptic speciation (e.g. Toussaint et al. 2012). It has also been used to identify potential management units in Octopus minor (Kang et al. 2012b).

One of the most investigated questions has concerned the true geographical extent of Octopus vulgaris. The first molecular studies to investigate this supported the removal of Octopus mimus (known from Central and South America) from the synonymy of Octopus vulgaris, the type locality of which is in the Mediterranean Sea (Söller et al. 2000; Warnke et al. 2000). Pérez-Losada et al. (2002b), using allozymes, confirmed that Octopus maya, a species endemic to the Yucatan Peninsula, was also distinct, and its position as sister to Octopus bimaculatus has recently been revealed by mitochondrial gene sequences (Juárez et al. 2012). In contrast, octopus specimens from South Africa and Senegal were shown to be conspecific with Octopus vulgaris (Warnke et al. 2000; Oosthuizen et al. 2004). Opinions differed over whether molecular sequences of specimens from Taiwan, Japan and Venezuela could be attributed to Octopus vulgaris (Oosthuizen et al. 2004; Warnke et al. 2004) as there is no set threshold genetic distance that differentiates species. Further specimens, from widely 

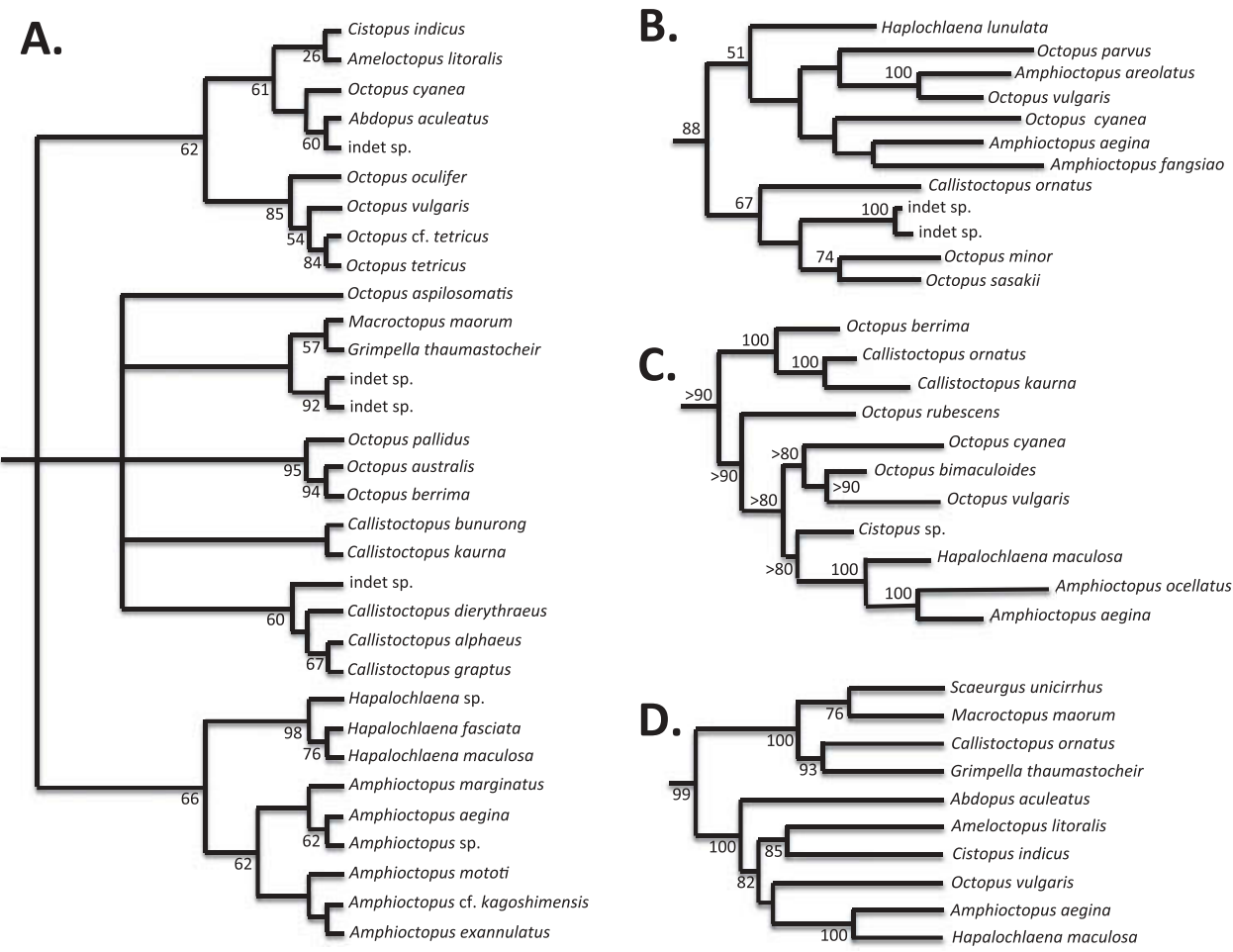

Figure 5. Maximum likelihood phylogenies of Octopodidae sensu Strugnell et al. 2013 (= Octopodinae sensu Sweeney and Roper 1998) based on (A) amino acid sequences of two mitochondrial genes: cytochrome oxidase subunit III and cytochrome b apoenzyme, and the nuclear gene Elongation Factor-1 $\alpha$ (Guzik et al. 2005); (B) 12S ribosomal RNA, 16S ribosomal RNA and cytochrome oxidase subunit I (Takumiya et al. 2005); (C) a multigene approach (four to ten genes depending on sequence availability) (Lindgren et al. 2012); (D) three nuclear and three mitochondrial genes tested and treated for saturation (Strugnell et al. 2013). All trees redrawn from original sources using updated nomenclature for clarity.

differentiated locations, were clearly required to solve the issue. Specimens from Brazil (Leite et al. 2008) were shown to be distinct from both Octopus vulgaris and Octopus mimus and were described as Octopus insularis. Guerra et al. (2010), using the DNA barcode gene COI, showed that specimens from South Africa, Senegal, Tristan de Cunha, France, Galicia, Saint Paul and Amsterdam Islands (in the Indian Ocean) and the Mediterranean all definitely pertained to Octopus vulgaris, while specimens from Japan clustered separately. Using COIII (and a slightly different set of samples), specimens from the Mediterranean, Senegal, South Africa, Tristan da Cunha (South Atlantic Ocean) and St Paul and Amsterdam Islands (Indian Ocean) all clustered together. Outside of this, but included in the Octopus sensu stricto clade, were specimens identified as Octopus bimaculatus, Octopus bimaculoides, Octopus mimus, Octopus tetricus and Octopus oculifer as well as specimens identified as Octopus vulgaris from Brazil, the Caribbean, Japan and Taiwan. The relationships between these were not well resolved and clearly there is scope for further work. One of the problems is that studies have often focused on a single gene, whereas what is really required is 
a global collection with all samples sequenced for multiple genes. Nonetheless, even though Octopus vulgaris has planktonic larvae with the potential for wide dispersal, it is remarkable that its distribution extends from the Atlantic into the Indian Ocean, especially as subtle population structuring has been found on a local scale within the Mediterranean (Keskin and Atar 2011) and two quite different (but conspecific) lineages have been reported from South Africa (Teske et al. 2007).

Population-level studies within octopods for the most part have used microsatellite markers and have focused on commercial species such as Octopus vulgaris (Greatorex et al. 2000; Casu et al. 2002; Murphy et al. 2002; Oosthuizen et al. 2004; Cabranes et al. 2008; Moreira et al. 2011; Zuo et al. 2012), Macroctopus maorum (Doubleday et al. 2009), Octopus pallidus (Higgins and Burridge 2012), Octopus maya (Juárez et al. 2010) and Octopus minor (Zuo et al. 2011; Kang et al. 2012a) although markers have also been developed (Strugnell et al. 2009b, 2009c) to attempt to answer broader questions about connectivity (e.g. Strugnell et al. 2012).

A few studies have also used microsatellite analysis to study paternity and these have revealed that multiple paternity is not uncommon (Voight and Feldheim 2009; Quinteiro et al. 2011).

\section{Spirulida}

There are few studies including multiple spirulids. Generally, Spirula is considered to comprise a single species; however, Warnke (2007) suggested that more than one species might exist. Strugnell et al. (2006b) showed that it was possible to obtain usable DNA from beach-washed shells and, more recently, DNA has been extracted from dead specimens (but with soft tissue attached) confirming that most likely there is a single species with a global distribution (Haring et al. 2012).

\section{Sepiida}

Sepiida comprises all known cuttlefishes. Current classifications (e.g. Young et al. 2012) assign all species to just three genera: Sepiella, Metasepia and Sepia. Sepiella is well defined with a clear synapomorphy (a subcutaneous gland opening caudally on the mantle). Metasepia species are united mainly by their reduced cuttlebone. Sepia contains all other $(\sim 100)$ sepiid species. Additional characters are required to define phylogenetic relationships within Sepia (Khromov et al. 1998). Many genus names exist within Sepiida, but until our understanding of relationships improves it is difficult to apply them. There are few molecular studies containing a large number of sepiids: phylogenies from several of the most extensive studies are illustrated (Figure 6). As pointed out by Bonnaud et al. (2005) there seems to be very little clustering by geographic location. The most noticeable relationship is between Sepia officinalis and Sepiella (Bonnaud et al. 2006; Yoshida et al. 2010; Lindgren et al. 2012). Yoshida et al. (2010) recovered several monophyletic groups and found support for the subgenera Acanthosepion and Doratosepion (Figure 6B). Apart from the paucity of studies, one of the problems with this group is that no consistent set of genes has been used to clarify relationships. Several studies have included COI and 16S (Lin et al. 2004; Takumiya et al. 2005; Yoshida et al. 2006; Lindgren et al. 2012), although Bonnaud et al. (2006) used 16S, 12S and COII; Yoshida et al. (2010) used COI, Cytb and 

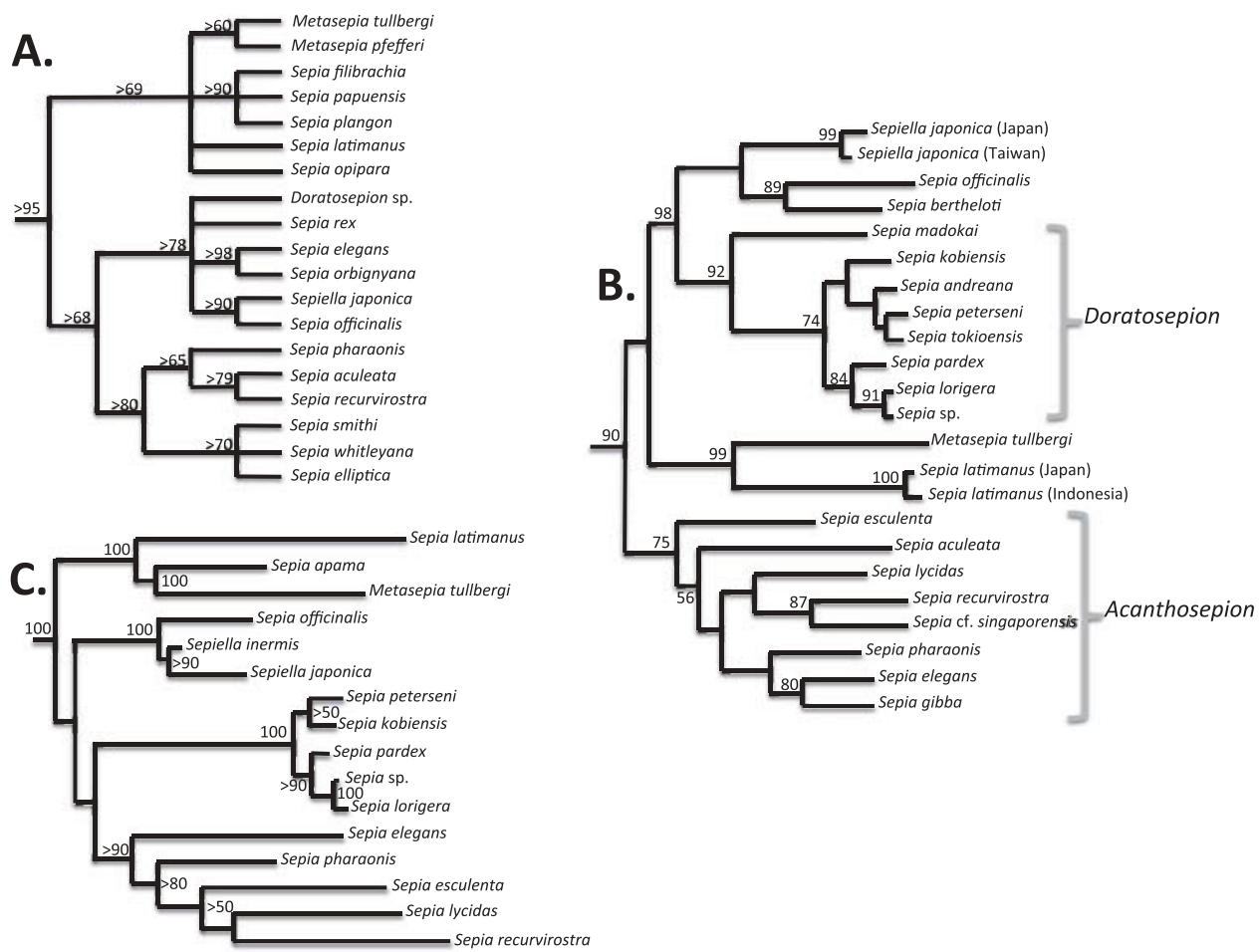

Figure 6. Relationships among Sepiida. (A) Consensus tree based on 12S rRNA, 16S rRNA, cytochrome oxidase subunit II (Bonnaud et al. 2006); (B) maximum likelihood tree of cytochrome oxidase subunit I, cytochrome b and ND5 combined (Yoshida et al. 2010); (C) whole evidence approach using four to ten genes (Lindgren et al. 2012). Trees redrawn from original sources.

NADH dehydrogenase 5 (ND5); and Dai et al. (2012) restricted their study to COI, the barcode gene. This means that studies rarely include the same taxa because each dataset is new, rather than building on an existing set of sequences already available in GenBank. Nonetheless, there is some congruence between the trees (Figure 6). With nearly 100 species in the genus Sepia, this is certainly a group that could benefit from more extensive molecular work.

There has been some targeted molecular work on specific species groups. For example, Anderson et al. $(2007,2011)$ targeted the Sepia pharaonis species complex. They found five clades, each of which probably represents a distinct species, but concluded further work from other parts of the range was required to provide definite answers.

Most molecular work on sepiids has in fact focused on populations of a particular species often employing microsatellite markers (e.g. Shaw and Pérez-Losada 2000; Zheng et al. 2001, 2005, 2007, 2009; Pérez-Losada et al. 2002a, 2007; Kassahn et al. 2003; Garoia et al. 2004; Wolfram et al. 2006a, 2006b; Wu et al. 2010), although sometimes using mitochondrial markers (e.g. Turan and Yaglioglu 2010). This focus on population biology is not surprising, given the commercial worth of many of 
these species and therefore the focus on fisheries biology and stock delimitation. Microsatellite markers have also been used to assess paternity and mating behaviour in Sepia apama, the giant Australian cuttlefish (Shaw 2003; Naud et al. 2004, 2005).

\section{Sepiolida}

Molecular phylogenetic analyses of sepiolids have also been limited. An early study searching for parallel speciation pattern in sepiolids and their bioluminous bacterial symbionts recovered monophyletic genera, but the tree topology did not support subfamily relationships (Nishiguchi et al. 1998). In a subsequent study investigating the evolution of bacteriogenic light organs in squids, Nishiguchi et al. (2004) found limited support for any established relationships. Not even any of the genera for which more than one species was included (Sepiola, Euprymna and Sepietta) were recovered as monophyletic. Lindgren et al. (2012), using four to ten genes depending on sequence availability, did find some resolution. This study supported monophyly of Sepiadariidae (= Sepioloidea + Sepiadarium) and confirmed Sepiadariidae as sister taxon to Sepiolidae, so supporting a monophyletic Sepiolida (see previous). At subfamily level this study found Sepiolinae (13 included species) to be monophyletic and Rossiinae (two included species) to be monophyletic, but found Heteroteuthinae (three included species) to be polyphyletic. Within Sepiolinae, the study supported a monophyletic Euprymna (having excluded some sequences available on GenBank identified as contaminants), but still found Sepiola and Sepietta to be polyphyletic. A phylogenetic analysis of relationships with Sepiolinae using the COI barcode gene also failed to recover monophyletic genera (Groenenberg et al. 2009) but did identify a previously overlooked species, illustrating the usefulness of the barcode gene at this level. Groenenberg et al. (2009) identified several "contaminants" among sepiolid sequences on GenBank and future studies on sepiolids are advised to consult this and Lindgren et al. (2012) for further details regarding these contaminants.

One particularly interesting facet of the sepiolid squids is their well-studied mutualistic association with the light-producing bacteria from the genus Vibrio, which is found in at least 26 species from five sepiolid genera (e.g. McFall-Ngai 1999; Nishiguchi 2002; Nishiguchi et al. 2004; Nyholm and Nishiguchi 2008; Zamborsky and Nishiguchi 2011). In this association, the environmentally transmitted bacteria (e.g. Visik and McFall-Ngai 2000; Kimbell and McFall-Ngai 2003; Nyholm and McFall-Ngai 2003; Jones and Nishiguchi 2006) are taken up by the squid into a specialized light organ (e.g. McFall-Ngai and Montgomery 1990; Fidiopiastis et al. 1998; Nishiguchi et al. 1998). The light produced is used by the squid to counterilluminate, specifically to match the intensity of down-welling moonlight to find prey and avoid potential predators (Jones and Nishiguchi 2004). To better understand the evolution of this mutualism, Nishiguchi et al. (1998) generated molecular phylogenies for both host sepiolid squids (internal transcribed spacer regions, and COI) and bacterial symbionts (glyceraldehyde-3-phosphate). The resulting phylogenetic trees revealed congruence, which provided new evidence for the presence of co-evolution. However, a subsequent study (Dunlap et al. 2007) revealed that the original study may have suffered from some mispriming of symbiont sequences. A reanalysis of corrected data (Dunlap et al. 2007) failed to find congruence between host and symbiont phylogenies. 
Similar mutualisms are also present in several loliginid species (e.g. Herring 1988; Guerrero-Ferreira and Nishiguchi 2007; Guerrero-Ferreira et al. 2013), and these provide an interesting example of convergent evolution (Lindgren et al. 2012).

\section{Myopsida}

Early work using allozyme electrophoresis (Brierley and Thorpe 1994; Brierley et al. 1996) attempted to address some of the systematic problems within Loliginidae. This work confirmed that several species should be placed in genera other than Loligo but could not resolve relationships within the family. Anderson (2000a) conducted the first large-scale phylogenetic study of loliginids wherein he analysed morphological, allozyme and molecular data for 19 species of loliginid squid. This work showed that there was marked geographic clustering within loliginid species with most American species, for example, clustering together in the genus Doryteuthis. Additionally, there appeared to be an East Atlantic clade and a clade of Indo-West Pacific species. The tree also placed Sepioteuthis as sister to the other loliginids, supporting morphological hypotheses that this genus is a Tethyan relict. The revised systematics published by Vecchione et al. (2005) reflects these molecular findings as well as an analysis of a combined morphological and molecular dataset (Anderson 2000b). Anderson (2000a) also found Uroteuthis, which exhibits bacterially mediated bioluminescence, paraphyletic with respect to the non-luminescent Loliolus. This is further supported by more recent work (Anderson et al. 2013). Sales et al. (2013) presented phylogenetic analyses which supported many of the generic groupings determined by Vecchione et al. (2005) and revealed genetic structure within several taxa known, or suspected, to comprise cryptic species.

Molecular studies have also been used to differentiate closely related species in conjunction with morphological work. Sin et al. (2009) combined morphology and COI barcoding in the differentiation of Uroteuthis edulis and Uroteuthis chinensis, two commercially important Asian species, while Anderson et al. (2008) used similar methodology (but additional gene sequences) in an attempt to differentiate European Alloteuthis species. In both cases, the molecular work allowed the assessment of the reliability of morphological characters used for identification purposes. The barcoding study of Chinese waters by Dai et al. (2012) included several loliginid species and recovered two separate clades of Loliolus beka, suggesting the presence of cryptic species in this nominal taxon. The barcode gene has also been used to study recent demographic expansion (using neutrality tests and Bayesian skyline analysis) in Doryteuthis gahi (Ibáñez et al. 2012). As mentioned above, several nominal species are thought to comprise cryptic species. Recent isolation and characterization of microsatellite markers in Sepioteuthis lessoniana will probably help to resolve the taxonomy of this species complex at least (Zheng et al. 2012b).

Multiple studies have used molecular techniques to understand recent and present gene flow in loliginid species, not least because of their commercial importance (e.g. Shaw 1997; Reichow and Smith 1999, 2001; Shaw et al. 1999, 2004, 2010; Herke and Foltz 2002; Shaw and Adcock 2002; Guarniero et al. 2003; Garoia et al. 2004; Buresch et al. 2006; Ito et al. 2006; Naud and Shaw 2008). There have also been a number of intriguing studies looking at the mating behaviour and fertilization dynamics of loliginid species using microsatellite markers (e.g. Shaw and Boyle 1997; Emery et al. 
2000, 2001; Maxwell et al. 2000; Buresch et al. 2001, 2009; Iwata et al. 2003; Shaw 2003; van Camp et al. 2003, 2004; Shaw and Sauer 2004; Iwata et al. 2005).

\section{Oegopsida}

Comprising more than 20 families, Oegopsida is easily the most diverse decapodiform order. Early phylogenetic studies found very little resolution among families, although several supported the monophyly of particular families. For example, Bonnaud et al. (1994) included 13 oegopsids and recovered an enoploteuthid clade (three spp.) and an ommastrephid clade (four spp.); Carlini and Graves (1999) included 23 oegopsids and recovered a gonatid clade (two spp.), an enoploteuthid clade (two spp.) and an ommastrephid clade (two spp.); and Carlini et al. (2000) included 20 oegposid genera and recovered a gonatid clade (two genera), a cranchiid clade (two genera) and a cycloteuthid clade (two genera). By far the most extensive studies however have been those of Lindgren (2010) and Lindgren et al. (2012); Lindgren (2010) included multiple representatives from 14 oegopsid families as well as single representatives from eight other families. Of the families with multiple representatives, only Mastigoteuthidae was not recovered as monophyletic. Additionally, this study, which was based on three nuclear (18S rRNA, 28S rRNA, histone H3) and two mitochondrial (COI, 12S rRNA) genes, recovered several deeper-level relationships. For example, a close relationship, which is also supported by morphological data, was found for several distinct groups: Pyroteuthidae and Enoploteuthidae; Histioteuthidae and Psychroteuthidae; and Lepidoteuthidae and Octopoteuthidae. Lindgren et al. (2012) analysed many of the same sequences but included data available on GenBank used in previous studies (e.g. Carlini and Graves 1999; Strugnell et al. 2005, etc.). This study further recovered relationships between Chiroteuthidae and Batoteuthidae and between Magnapinnidae, Joubinateuthidae and Mastigoteuthidae, families which have been purported to be closely related based on some morphological similarities (Young and Vecchione 2008).

The relationships within three oegopsid families, Onychoteuthidae, Gonatidae and Ommastrephidae, have been studied more extensively. Onychoteuthidae has always been a problematic family and has undergone recent systematic revision (Bolstad 2010). Bonnaud et al. (1998) showed that both Onychoteuthis and Moroteuthis (as they were then understood) were probably polyphyletic (Figure 7A) using 16S rRNA. Suggestions that the genus Onykia, representatives of which were mostly juveniles, was synonymous with Moroteuthis were investigated by Wakabayashi et al. (2007). They used COI, the barcode gene, to show that paralarvae assigned to Onykia fell in a clade with specimens of adult Moroteuthis and suggested that all species previously assigned to Moroteuthis, except Moroteuthis knipovitchi, which was genetically distant and morphologically distinct, should be placed in Onykia, which had priority. Bolstad (2010) later erected the genus Fillipovia to accommodate Fillipovia knipovitchi. Using five genes (18S rRNA, 28S rRNA, histone H3, 16S rRNA and COI), Lindgren (2010) also investigated relationships within the family and found Onykia to be polyphyletic with Onykia carriboea as sister taxon to Ancistroteuthis lichtensteinii and far removed from its congener Onykia robusta (Figure 7B). A similar result was recovered by a subsequent study using similar genes (Lindgren et al. 2012; Figure 7C). 

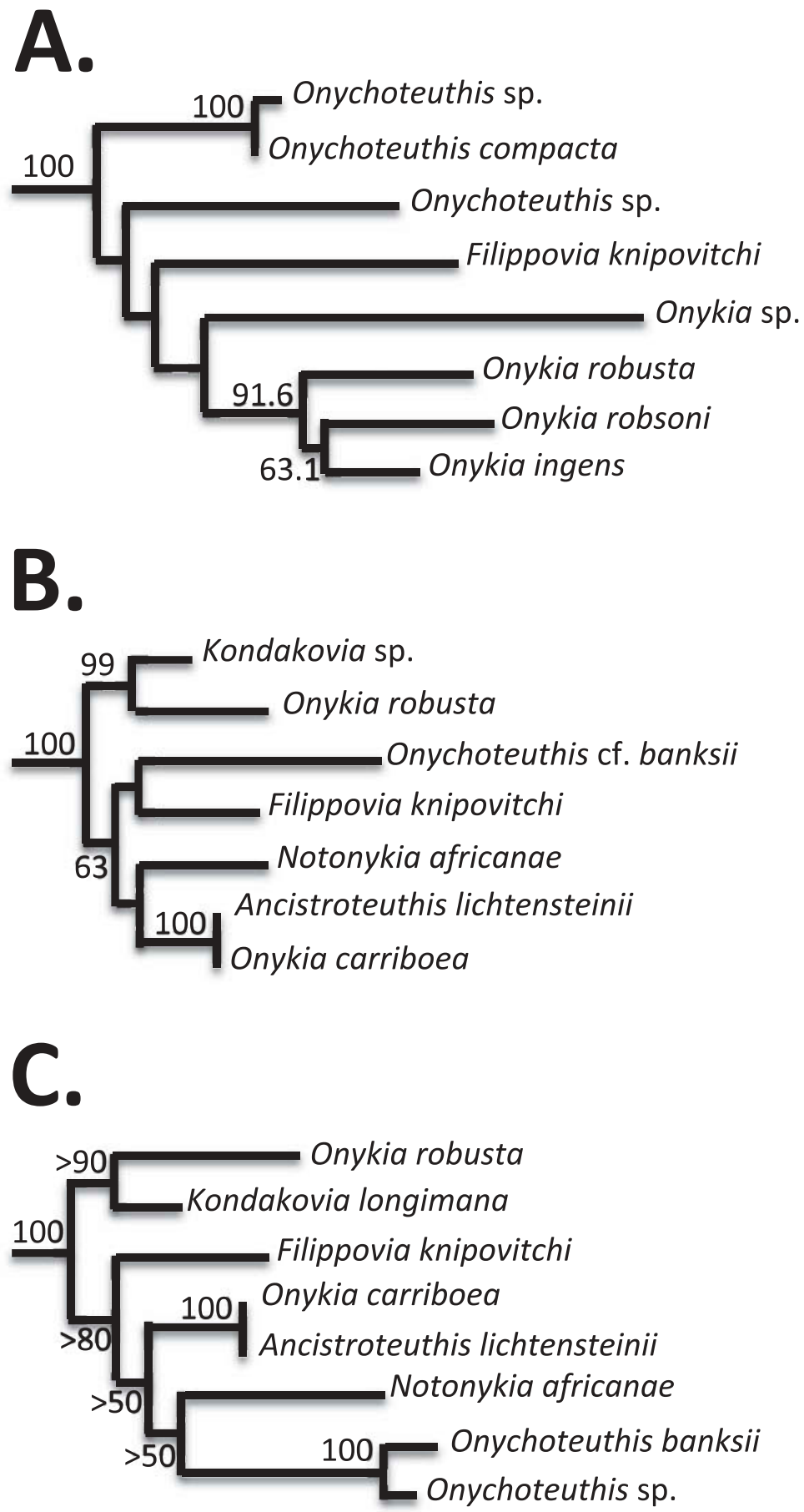

Figure 7. Relationships within Onychoteuthidae. (A) Neighbour-joining tree based on 16S ribosomal RNA (Bonnaud et al. 1998); (B) maximum likelihood tree of five genes (see text) combined (Lindgren 2010); (C) maximum likelihood tree based on whole evidence approach using four to ten genes (Lindgren et al. 2012). All trees redrawn from original sources. Nomenclature uses systematic revision of Bolstad (2010). 
Lindgren et al. (2005) is the only molecular study to focus on Gonatidae. Using three mitochondrial genes (16S rRNA, 12S rRNA and COI), including 14 species from the four nominal gonatid genera and building trees implementing direct optimization in POY (see earlier), Lindgren et al. (2005) found all genera (Gonatus, Gonatopsis, Berryteuthis) except Eogonatus (which is monospecific) to be polyphyletic. Given the wide array of morphological and behavioural diversity (e.g. Seibel et al. 2000), more study of the evolutionary relationships within this family is needed.

The ommastrephids have received slightly more attention (at least in some regions). Carlini et al. (2006) studied the genus Illex. They recovered four clades suggesting that four species do exist (Illex coindetii, Illex oxygonius, Illex argentinus and Illex illecebrosus) but they found that morphological characters did not easily separate the species. Furthermore, they found two species in the East Atlantic, which requires further investigation because only Illex coindetii is reported to occur there. Wakabayashi et al. (2006) amplified partial COI sequences from four species of Ommastrephidae (Ommastrephes bartramii, Sthenoteuthis oualaniensis, Eucleoteuthis luminosa and Hyaloteuthis pelagica) and digested them with endonucleases. They found that the restriction fragments were species specific and they were able to use this method to identify paralarvae. Where restriction fragments failed to place a paralarva, the authors were able to resolve its identity through sequencing of the amplified product. A maximum likelihood tree based on COI transversions did not recover Ommastrephinae as monophyletic but did more or less reflect morphological hypotheses. Ommastrephinae was recovered as monophyletic in a previous study using $16 \mathrm{~S}$ rRNA (Wada et al. 2002 cited in Wakabashi et al. 2006). It has also recently been recovered in a study using 16S rRNA and COI partial sequences (Wakabayashi et al. 2012a). This latest study, including 15 species in 10 genera and including all three subfamilies, recovered all the subfamilies as monophyletic in all analyses bar one. However, within Todarodinae, the authors found Todarodes and Nototodarus to be polyphyletic. Todarodes fillippovae was consistently (five out of six topologies) the sister taxon to Martialia hyadesi and distant from Todarodes pacificus. Todarodes pacificus was consistently placed in a clade among Nototodarus species. Japanese researchers have also studied the intriguing amphitropical distribution of Ommastrephes bartramii. They found a fairly homogeneous distribution in the North Pacific, but found clear genetic differentiation between North Pacific and South Atlantic samples, although this differentiation was less than would be expected between separate species (Wakabayashi et al. 2012b). Significant differences have also been found between the North Pacific and the Indian Ocean (Kurosaka et al. 2012).

As in other groups, it is the commercially exploited species that have attracted most attention. Ibáñez et al. (2011) investigated the genetic diversity and demographic history of Dosidicus gigas, a species that has attracted much recent attention because of its range shift (Keyl et al. 2008). Analyses of data based on the COI barcode gene indicate that there is a single homogeneous population of Dosidicus gigas in the Humboldt Current System but this has undergone significant population expansion since the last glacial maximum (Ibáñez et al. 2011). The changing geographic distribution of Dosidicus gigas has provoked intense study of this species and molecular identification of paralarvae has proved to be a useful technique. Distinguishing different ommastrephid paralarvae using morphology is extremely difficult and molecular identification is being used increasingly frequently (e.g. Gilly et al. 2006; Ramos-Castillejos et al. 2010; Staaf et al. 2013). 
Apart from the work on Ommastrephes bartramii and Dosidicus gigas outlined above, population studies have targeted a number of other ommastrephid species including Illex argentinus (Adcock et al. 1999a, 1999b), Illex coindetii (Dillane et al. 2000) and Todaropsis eblanae (Dillane et al. 2000, 2005). Studies have also been conducted on Thysanoteuthis rhombus (Kitaura et al. 1998), the only species within the family Thysanoteuthidae, which is commercially exploited in Japanese waters. This study found a remarkable lack of genetic differentiation even between samples from either side of the Pacific, possibly reflecting the motility of egg masses (Nigmatullin et al. 1995) in this species. Limited genetic heterogeneity has been found between widely spaced sub-Antarctic populations of Onykia ingens and it has been suggested that dispersal of eggs and paralarvae in strong Southern Ocean currents, coupled with slow development times at subpolar temperatures, may explain this relative homogeneity (Sands et al. 2003).

Recently, Winklemann et al. (2013) published population analyses of the giant squid, Architeuthis dux, based on the whole mitochondrial genome sequences of 43 specimens collected worldwide. They found remarkably little structure, confirming that just a single species of Architeuthis exists, but also found exceptionally low nucleotide diversity. The reason for such low diversity was not clear.

\section{Bathyteuthida}

Although bathyteuthids have been consistently recovered as the sister taxon to Oegopsida (Strugnell and Nishiguchi 2007; Lindgren 2010) few studies have included many representatives. This small group currently comprises six species, three in each of two monogeneric families: Chtenopterygidae and Bathyteuthidae. Lindgren et al. (2012) included three described and two undescribed species of Bathyteuthida and confirmed monophyly of each genus and the order.

\section{Nautilus}

There have been few molecular studies completed on Nautilus to date; however the few published studies have yielded valuable information. Studies have confirmed the validity of the genus Allonautilus and its sister-taxon relationship with Nautilus (Bonacum et al. 2011). However, they have also suggested that Nautilus pompilius comprises many evolutionarily independent lineages and there are in fact many more species present in the Indo Pacific than are currently recognized (Sinclair et al. 2007, 2011; Bonacum et al. 2011; Williams et al. 2012). These are important data because of the susceptibility of Nautilus populations to intense fishery activity (Dunstan et al. 2010). Again, these studies, all of which included but were not necessarily limited to COI sequence data, showed the utility of the barcode gene in elucidating the presence of cryptic species.

\section{Conclusions}

Molecular methods have yielded valuable data about relationships within orders and families but there is still much to learn. The existing studies provide guidance as to which genes are appropriate at which taxonomic levels. Our better understanding of the problems of saturation, base composition bias and long-branch attraction 
now allow for these issues to be addressed directly, decreasing their future impact. Representative taxon coverage is an important issue, both with respect to ingroup and outgroup choices. With families, and even genera, exhibiting global distributions, international co-operation is paramount.

Techniques that were relatively new to cephalopod biology 10 years ago (see review by Shaw 2002), such as DNA barcoding, are now cheap, simple and accessible to all. In fact, the potential of DNA barcoding (Strugnell and Lindgren 2007) provides a real opportunity to delimit the species within species complexes, for example the Sepia pharaonis complex, and complexes within nautiloids and Octopodidae. It also offers the potential to identify truly cryptic species that would not be recognized by morphology alone and also allows species to be identified where taxonomic expertise is lacking, an issue particularly important in fisheries biology (e.g. Undheim et al. 2010).

The occurrence of gene and genome duplication events remains intriguing, and karyotype and genome size studies of additional species, particularly oegopsids, will aid our understanding of these processes and the impact that they have had on the evolution of different coleoid lineages. A better understanding of the events that have taken place is particularly important because these large duplications cause considerable difficulties during the assembly stage of cephalopod whole genome projects.

Genomic studies will undoubtedly resolve many more relationships among cephalopod higher taxa, just as they have done among molluscan classes. The cost per megabase of raw sequence has declined dramatically over a 5-year period - from approximately US\$ 1000 in October 2004 to 10 cents in October 2011 (see http:// www.genome.gov/sequencingcosts/) so "-omic" level phylogenetic approaches are now feasible. Phylogenetic studies of cephalopods using whole mitochondrial genomes have already been published and are likely to increase in frequency. Phylogenetic studies based on the transcriptome have been published on molluscan classes (incorporating several hundred genes) and it is likely that studies investigating higher-level cephalopod relationships using transcriptome data will be published shortly. At least six cephalopod whole genome projects are underway and these data will open up the possibilities of phylogenetic studies of cephalopods using whole genomes and these will probably take the form of not only "standard" molecular phylogenetics of sequence data, but also investigation of higher-order characters such as gene content and gene order. Large amounts of sequence data (obtained either through genomic or transcriptomic projects) will allow "targeted capture" enabling homologous sequences to be obtained from large numbers of species, including those which are preserved and housed in museums.

At the CIAC 2012 meeting in Florianópolis Brazil, poster and oral presentations showed that molecular techniques are being widely applied to solve questions in cephalopod biology. Studies were presented investigating population biology (e.g. of the giant squid), species complexes (e.g. of Sepioteuthis lessoniana), and phylogeography (e.g. of octopus species). Studies investigating the phylogeny of various groups including Loliolini, Onychoteuthidae and Mastigoteuthidae were presented. And finally, several presentations were made on genomic topics, including whole mitochondrial genomes of some octopus species, the full pygmy squid genome, which is likely to be completed shortly, as well as a review by the CephSeq consortium, which is striving to provide cohesion among research groups pursuing genomics work.

Understanding the evolutionary relationships of cephalopods will accelerate and facilitate our understanding of the evolution of many interesting traits of cephalopods 
including colour patterns, vision, body plan complexity, toxicity and "intelligence" and is particularly important because of their role as model organisms to study the nervous system and eukaryotic-prokaryotic interactions among others.

\section{Acknowledgements}

We would like to thank Jaruwat Nabhitabhata for informing us of the chromosome number of Sepiella inermis given in a paper written in Thai. Laure Bonnaud, Patrizia Jereb and Mike Vecchione helped us secure difficult to obtain references. Kathie Way, Natural History Museum, London, kindly provided a copy of Patterson (1969). Laure Bonnaud, Hidetaka Furuya, Michelle Guzik and Masa-aki Yoshida generously allowed us to redraw figures from their published manuscripts. The constructive reviews of Frank (Andy) Anderson and an anonymous referee, and the careful editing of José Marian, undoubtedly improved this paper.

\section{References}

Aagasen L, Petersen G, Sedberg O. 2005. Sequence length variation, indel costs, and congruence in sensisitivity analysis. Cladistics. 21:5-30.

Acosta-Jofré MS, Sahade R, Laudien J, Chiappero MB. 2012. A contribution to the understanding of phylogenetic relationships among species of the genus Octopus (Octopodidae: Cephalopoda). Sci Marina. 76:311-318.

Adcock GJ, Carvalho GR, Rodhouse PG, Shaw PW. 1999a. Highly polymorphic microsatellite loci of the heavily fished squid genus Illex (Ommastrephidae). Mol Ecol. 8:165-167.

Adcock GJ, Shaw PW, Rodhouse PG, Carvalho GR. 1999b. Microsatellite analysis of genetic diversity in the squid Illex argentinus during a period of intensive fishing. Mar Ecol Prog Ser. 187:171-178.

Akasaki T, Nikaido M, Tsuchlya K, Segawa S, Hasegawa M, Okada N. 2006. Extensive mitochondrial gene arrangements in coleoid Cephalopoda and their phylogenetic implications. Mol Phylogenet Evol. 38:648-658.

Albertin CB, Bonnaud L, Brown CT, Crookes-Goodson WJ, da Fonseca R, Di Cristo C, Dilkes BP, Edsinger-Gonzales E, Freemen RM, Hanlon RT, et al. 2012. Cephalopod Genomics: A Plan of Strategies and Organization. Stand Genomic Sci. 7:175-188.

Allcock AL, Barratt I, Eléaume M, Linse K, Norman MD, Smith PJ, Steinke D, Stevens DW, Strugnell JM. 2011b. Cryptic speciation and the circumpolarity debate: a case study on endemic Southern Ocean octopuses using the coxI barcode of life. Deep Sea Res II. 58:242-249.

Allcock AL, Cooke IR, Strugnell JM. 2011a. What can the mitochondrial genome reveal about higher-level phylogeny of the molluscan class Cephalopoda?. Zool J Linn Soc. 161:573-586.

Allcock AL, Piertney SB. 2002. Evolutionary relationships of southern ocean Octopodidae (Cephalopoda: Octopoda) and a new diagnosis of Pareledone. Mar Biol. 140:129-135.

Allcock AL, Strugnell JM, Johnson MP. 2008. How useful are the recommended counts and indices in the systematics of the Octopodidae (Mollusca: Cephalopoda). Biol J Linn Soc. 95:205-218.

Allcock AL, Strugnell JM, Prodohl P, Piatkowski U, Vecchione M. 2007. A new species of Pareledone (Cephalopoda: Octopodidae) from Antarctic Peninsula Waters. Polar Biol. 30:883-893.

Allcock AL, Strugnell JM, Ruggiero H, Collins MA. 2006. Redescription of the deep-sea octopod Benthoctopus normani (Massy 1907) and a description of a new species from the Northeast Atlantic. Mar Biol Res. 2:372-387. 
Anderson FE. 2000a. Phylogeny and historical biogeography of the loliginid squids (Mollusca: Cephalopoda) based on mitochondrial DNA sequence data. Mol Phylogenet Evol. 15:191-214.

Anderson FE. 2000b. Phylogenetic relationships among loliginid squids (Cephalopoda: Myopsida) based on analyses of multiple data sets. Zool J Linn Soc. 130:603-633.

Anderson FE, Bergman A, Cheng SH, Pankey MS, Valinassab T. 2013. Lights out: the evolution of bacterial bioluminescence in Loliginidae. Hydrobiologia. Published online. http://link. springer.com/article/10.1007\%2Fs10750-013-1599-1

Anderson FE, Engelke R, Jarrett K, Valinassab T, Mohamed KS, Asokan PK, Zacharia PU, Nootmorn P, Chotiyaputta C, Dunning M. 2011. Phylogeny of the Sepia pharaonis species complex (Cephalopoda: Sepiida) based on analyses of mitochondrial and nuclear DNA sequence data. J Moll Stud. 77:65-75.

Anderson FE, Pilsits A, Clutts S, Laptikhovsky V, Bello G, Balguerias E, Lipinski M, Nigmatulin C, Pereira JMF, Piatkowski U, et al. 2008. Systematics of Alloteuthis (Cephalopoda: Loliginidae) based on molecular and morphometric data. J Exp 1 Mar Biol Ecol. 364:99-109.

Anderson FE, Swofford DL. 2004. Should we be worried about long-branch attraction in real datasets? Investigations using metazoan 18S rDNA. Mol Phylogenet Evol. 33:440-451.

Anderson FE, Valinassab T, Ho C-W, Mohamed KS, Asokan PK, Rao GS, Nootmorn P, Chotiyaputta C, Dunning M, Lu C-C. 2007. Phylogeography of the pharaoh cuttle Sepia pharaonis based on partial mitochondrial 16S sequence data. Rev Fish Biol Fish. 17:345-352.

Barker FK, Lutzoni FM. 2002. The utility of the incongruence length difference test. Syst Biol. 51:625-627.

Barriga Sosa I, Beckenbach K, Hartwick B, Smith MJ. 1995. The molecular phylogeny of five eastern North Pacific octopus species. Mol Phylogenet Evol. 4:163-174.

Bizikov VA. 2004. The shell in Vampyropoda (Cephalopoda): Morphology, functional role and evolution. Ruthenica Suppl. 3:1-88.

Bolstad KSR. 2010. Systematics of the Onychoteuthidae Gray, 1847 (Cephalopoda: Oegopsida). Zootaxa. 2696:1-186.

Bonacum J, Landman NH, Mapes RH, White MM, White AJ, Irlam J. 2011. Evolutionary radiation of present-day Nautilus and Allonautilus. Am Malacol Bull. 29:77-93.

Bonnaud L, Boucher-Rodoni R, Monnerot M. 1994. Phylogeny of decapod cephalopods based on partial 16s rDNA nucleotide-sequences. Compt Rend Biol. 317:581-588.

Bonnaud L, Boucher-Rodoni R, Monnerot M. 1996. Relationship of some coleoid cephalopods established by 3' end of the 16S rDNA and cytochrome oxidase III gene sequence comparison. Am Malacol Bull. 12:87-90.

Bonnaud L, Boucher-Rodoni R, Monnerot M. 1997. Phylogeny of cephalopods inferred from mitochondrial DNA sequences. Mol Phylogenet Evol. 7:44-54.

Bonnaud L, Lu CC, Boucher-Rodoni R. 2006. Morphological character evolution and molecular trees in sepiids (Mollusca: Cephalopoda): is the cuttlebone a robust phylogenetic marker?. Biol J Linn Soc. 89:139-150.

Bonnaud L, Ozouf-Costaz C, Boucher-Rodoni R. 2004. A molecular and karyological approach to the taxonomy of Nautilus. Compt Rend Biol. 327:133-138.

Bonnaud L, Pichon D, Boucher-Rodoni R. 2005. Molecular approach of Decabrachia phylogeny: Is Idiosepius definitely not a sepiolid?. Phuket Mar Biol Cent Res Bull. 66:203-212.

Bonnaud L, Rodhouse PG, Boucher-Rodoni R. 1998. A phylogenetic study of the squid family Onychoteuthidae (Cephalopoda: Oegopsida). Proc Roy Soc B. 265:1761-1770.

Bonnaud L, Saihi A, Boucher-Rodoni R. 2002. Are 28S RDNA and 18S RDNA informative for cephalopod phylogeny?. Bull Mar Sci. 71:197-208.

Boonprakob P, Siripoonya P, Yodyingyuad U, Satayalai O, Sithigorngul P. 1977. Studies on embryonic development, karyotype, effects of physical factors on development and 
behavioral response to physical factors. Research Paper, Department of Biology, Faculty of Science, Chulalongkorn University. 50 p. (In Thai with English Abstract).

Boore JL. 2006. The complete sequence of the mitochondrial genome of Nautilus macromphalus (Mollusca: Cephalopoda). BMC Genomics. 7:182.

Boore JL, Collins TM, Stanton DD, Brown WM. 1995. Deducing arthropod phylogeny from mitochon drial DNA rearrangements. Nature. 376:163-165.

Boucher-Rodoni R, Bonnaud L. 1996. Biochemical and molecular approach to cephalopod phylogeny. Am Malacol Bull. 12:79-85.

Brierley AL, Allcock AL, Thrope JP, Clarke MR. 1996. Biochemical genetic evidence supporting the taxonomic separation of Loligo edulis and Loligo chinensis (Cephalopoda: Teuthoidea) from the genus Loligo. Mar Biol. 127:98-104.

Brierley AS, Thorpe JP. 1994. Biochemical genetic evidence sup- porting the taxonomic separation of Loligo gahi from the genus LoIigo. Antarctic Sci. 6:143-148.

Buresch KC, Gerlach G, Hanlon RT. 2006. Multiple genetic stocks of longfin squid Loligo pealeii in the NW Atlantic: stocks segregate inshore in summer but aggregate offshore in winter. Mar Ecol Prog Ser. 310:263-270.

Buresch KM, Hanlon RT, Maxwell MR, Ring S. 2001. Microsatellite DNA markers indicate a high frequency of multiple paternity within individual field-collected egg capsules of the squid Loligo pealeii. Mar Ecol Prog Ser. 210:161-165.

Buresch KC, Maxwell MR, Cox MR, Hanlon RT. 2009. Temporal dynamics of mating and paternity in the squid Loligo pealeii. Mar Ecol Prog Ser. 387:197-203.

Cabranes C, Fernandez-Rueda P, Martinez JL. 2008. Genetic structure of Octopus vulgaris around the Iberian Peninsula and Canary Islands as indicated by microsatellite DNA variation. ICES J Mar Sci. 65:12-16.

Carlini DB, Graves JE. 1999. Phylogenetic analysis of cytochrome c oxidase I sequences to determine higher-level relationships within the coleoid cephalopods. Bull Mar Sci. 64:57-76.

Carlini DB, Kunkle LK, Vecchione M. 2006. A molecular systematic evaluation of the squid genus Illex (Cephalopoda: Ommastrephidae) in the North Atlantic ocean and Mediterranean Sea. Mol Phylogenet Evol. 41:496-502.

Carlini DB, Reece KS, Graves JE. 2000. Actin gene family evolution and the phylogeny of coleoid cephalopods (Mollusca: Cephalopoda). Mol Biol Evol. 17:1353-1370.

Carlini DB, Young RE, Vecchione M. 2001. A molecular phylogeny of the Octopoda (Mollusca: Cephalopoda) evaluated in light of morphological evidence. Mol Phylogenet Evol. 21:388-397.

Casu M, Maltagliati F, Meloni M, Casu D, Cossu P, Binelli G, Curini-Galletti M, Castelli A. 2002. Genetic structure of Octopus vulgaris (Mollusca Cephalopoda) from the Mediterranean Sea as revealed by a microsatellite locus. Ital J Zool. 69:295-300.

Cheng R, Zheng X, Lin X, Yang J, Qi Li. 2012. Determination of the complete mitochondrial DNA sequence of Octopus minor. Mol Biol Rep. 39:3461-3470.

Colgan DJ, Donald J, Hutchings PA, Beacham E. 2008. Multi-gene analyses of the phylogenetic relationships among the Mollusca, Annelida and Arthropoda. Zool Stud. 47:338-351.

Colgan DJ, Hutchings PA, Brown S. 2001. Phylogenetic relationships within the Terebellomorpha. J Mar Biol Assoc UK. 81:763-773.

Colgan DJ, Ponder WF, Eggler PD. 2000. Gastropod evolutionary rates and phylogenetic relationships assessed using partial $28 \mathrm{~S}$ rDNA and histone $\mathrm{H} 3$ sequences. Zool Scr. 29:29-65.

Collins MA, Laptikhovsky V, Strugnell JM. 2010. Expanded description of Opisthoteuthis hardyi based on new specimens from the Patagonian slope. J Mar Biol Assoc UK. 90:605-611.

Collins MA, Villanueva R. 2006. Taxonomy, ecology and behaviour of the cirrate octopods. Oceanogr Mar Biol Ann Rev. 44:277-322. 
Cuccu D, Mereu M, Cannas R, Follesa MC, Cau A, Jereb P. 2009. Morphology, biology and molecular characterizations of Opisthoteuthis calypso (Cephalopoda: Octopoda) from the Sardinian Channel (central western Mediterranean). J Mar Biol Assoc UK. 89:1709-1715.

Dai L, Zheng X, Kong L, Li Q. 2012. DNA barcoding analysis of Coleoidea (Mollusca: Cephalopoda) from Chinese waters. Mol Ecol Resour. 12:437-447.

Darlu P, Lecointre G. 2002. When does the incongruence length difference test fail?. Mol Biol Evol. 19:432-437.

Dillane E, Galvin P, Coughlan J, Lipinski M, Cross TF. 2005. Genetic variation in the lesser flying squid Todaropsis eblanae (Cephalopoda Ommastrephidae) in east Atlantic and Mediterranean waters. Mar Ecol Prog Ser. 292:225-232.

Dillane E, Galvin P, Coughlan J, Rodhouse PGK, Cross TF. 2000. Polymorphic variable number of tandem repeat (VNTR) loci in the ommastrephid squid Illex coindetii and Todaropsis eblanae. Mol Ecol. 9:1002-1004.

Doubleday ZA, Semmens JM, Smolenski AJ, Shaw PW. 2009. Microsatellite DNA markers and morphometrics reveal a complex population structure in a merobenthic octopus species (Octopus maorum) in south-east Australia and New Zealand. Mar Biol. 156:1183-1192.

Dover GA. 1982. Molecular drive: A cohesive mode of species evolution. Nature. 299: 111-117.

Dowton M, Austin AD. 2002. Increased congruence does not necessarily indicate increased phylogenetic accuracy - The behavior of the ILD test in mixed-model analyses. Syst Biol. 51:19-31.

Dunlap PV, Ast JC, Kimura S, Fukui A, Yoshino T, Endo H. 2007. Phylogenetic analysis of host-symbiont specificity and codivergence in bioluminescent symbioses. Cladistics. 23:507-532.

Dunn CV, Hejnol A, Matus DQ, Pang K, Browne WE, Smith SA, Seaver E, Rouse GW, Obst M, Edgecombe GD, et al. 2008. Broad phylogenomic sampling improves resolution of the animal tree of life. Nature. 452:745-749.

Dunstan A, Alanis O, Marshall J. 2010. Nautilus pompilius fishing and population decline in the Philippines: A comparison with an unexploited Australian Nautilus population. Fish Res. 106:239-247.

Edgar RC. 2004. MUSCLE: a multiple sequence alignment method with reduced time and space complexity. BMC Bioinform. 5:113.

Emery AM, Shaw PW, Greatorex EC, Boyle PR, Noble LR. 2000. New microsatellite markers for assessment of paternity in the squid Loligo forbesi (Mollusca: Cephalopoda). Mol Ecol. 9:110-112.

Emery AM, Wilson IJ, Craig S, Boyle PR, Noble LR. 2001. Assignment of paternity groups without access to parental genotypes: multiple mating and developmental plasticity in squid. Mol Ecol. 10:1265-1278.

Farris JS, Kallersjo M, Kluge A, Bult C. 1995. Testing significance of incongruence. Cladistics. 10:315-319.

Felsenstein J. 2004. Inferring Phylogenies. Massachussets: Sinaeur Associates; p. 580p.

Fidiopiastis P, Boletzky SV, Ruby EG. 1998. A new niche for Vibrio logei, the predominant light organ symbiont of squids in the genus Sepiola. J Bacteriol. 180:59-64.

Folmer O, Black M, Hoeh W, Lutz R, Vrijenhoek R. 1994. DNA primers for amplification of mitochondrial cytochrome c oxidase subunit I from diverse metazoan invertebrates. Mol Mar Biol Biotechnol. 3:294-297.

Fuchs D, Bracchi G, Weis R. New octopods (Cephalopoda: Coleoidea) from the Late Cretaceous (Upper Cenomanian) of Hakel and Hadjoula Lebanon. Palaeontology. 52:65-81.

Gao Y-M, Natsukari Y. 1990. Karyological studies on seven cephalopods. Venus. 49:126-145.

Garoia F, Guarniero I, Ramsak A, Ungaro N, Landi M, Piccinetti C, Mannini P, Tinti F. 2004. Microsatellite DNA variation reveals high gene flow and panmictic populations in 
the Adriatic shared stocks of the European squid and cuttlefish (Cephalopoda). Heredity. 93:166-174.

Gegenbaur C. 1878. Grundriss der vergleichenden Anatomie. Zweite verbesswerte Auflage. Leipzig: W. Engelmann; p. 655 p.

Gilly WF, Elliger CA, Salinas CA, Camarillo-Coop S, Bazzino G, Beman M. 2006. Spawning by jumbo squid (Dosidicus gigas) in the Pedro Mártir Basin, Gulf of California, Mexico. Mar Ecol Prog Ser. 313:125-133.

Giribet G, Okusu A, Lindgren AR, Huff SW, Schrodl M, Nishiguchi MK. 2006. Evidence for a clade composed of molluscs with serially repeated structures: Monoplacophorans are related to chitons. Proc Natl Acad Sci. 103:7723-7728.

Gleadall IG. 2004. Some old and new genera of octopus. Interdiscip Inf Sci. 102:99-112.

Goloboff PA, Catalano SA, Mirande JM, Szumik CA, Arias JS, Kallersjo M, Farris JS. 2009. Phylogenetic analysis of 73060 taxa corroborates major eukaryotic groups. Cladistics. 25:211-230.

Goloboff PA, Farris JS, Nixon KC. 2004. TNT. Cladistics. 20:84-84.

Greatorex EC, Jones CS, Murphy J, Key LN, Emery AM, Boyle PR. 2000. Microsatellite markers for investigating population structure in Octopus vulgaris (Mollusca: Cephalopoda). Mol Ecol. 9:641-642.

Groenenberg DSJ, Goud J, De Heij A, Gittenberger E. 2009. Molecular phylogeny of North Sea Sepiolinae (Cephalopoda: Sepiolidae) reveals an overlooked Sepiola species. J Moll Stud. 75:361-369.

Guarniero I, Garoia F, Di Placido R, Ramsak A, Mannini P, Tinti F. 2003. Species-specific microsatellite loci for the European squid (Loligo vulgaris). Mol Ecol Notes. 3:312-313.

Guerra A, Roura A, Gonzalez AF, Pascual S, Cherel Y, Pérez-Losada M. 2010. Morphological and genetic evidence that Octopus vulgaris Cuvier 1797 inhabits Amsterdam and Saint Paul Islands (southern Indian Ocean). ICES J Mar Sci. 67:1401-1407.

Guerrero-Ferreira RC, Gorman C, Chavez-Dozal AA, Willie S, Nishiguchi MK. 2013. Characterization of the bacterial diversity of Indo-West Pacific loliginid and sepiolid squid light organs. Microb Ecol. 65:214-226.

Guerrero-Ferreira RC, Nishiguchi MK. 2007. Biodiversity among luminescent symbionts from squid of the genera Uroteuthis, Loliolus and Euprymna (Mollusca: Cephalopoda). Cladistics. 23:497-506.

Guzik MT, Norman MD, Crozier RH. 2005. Molecular phylogeny of the benthic shallow-water octopuses (Cephalopoda: Octopodinae). Mol Phylogenet Evol. 37:235-248.

Hallinan NM, Lindberg DR. 2011. Comparative analysis of chromosome counts infers three pealeopolyploides in the Mollusca. Genome Biol Evol. 3:1150-1163.

Haring E, Kruckenhauser L, Lukeneder A. 2012. New DNA sequence data on the enigmatic Spirula spirula (Linnaeus, 1758) (Decabrachia, suborder Spirulina). Ann Naturhist Mus Wien B. 113:37-48.

Haszprunar G. 2000. Is the Aplacophora monophyletic? A cladisitic point of view. Am Malacol Bull. 15:115-130.

Hatsheck B. 1891. Foreward to Blumrich J. 1891. Das Integument der Chitonen. Zeitschr Wissen Zool. 52:404-476. plates 23-30.

Herke SW, Foltz DW. 2002. Phylogeography of two squid (Loligo pealei and L-plei) in the Gulf of Mexico and northwestern Atlantic Ocean. Mar Biol. 140:103-115.

Herring PJ. 1988. Luminescent organs. In: Wilbur KM, editor. The Mollusca. 11th edition. San Diego: Academic Press;449-485.

Higgins KL, Burridge CP. 2012. Development of eight polymorphic microsatellite loci in the cephalopod Octopus pallidus. Conserv Genet Resour. 4:97-99.

Hinegardner R. 1974. Cellular DNA content of the Mollusca. Comp Biochem Physiol. 47:447-460. 
Huelsenbeck JP, Hillis DM. 1993. Success of Phylogenetic Methods in the Four-Taxon Case. Syst Biol. 42:247-264.

Ibáñez CM, Argueelles J, Yamashiro C, Adasme L, Cespedes R, Poulin E. 2012. Spatial genetic structure and demographic inference of the Patagonian squid Doryteuthis gahi in the southeastern Pacific Ocean. J Mar Biol Assoc UK. 92:197-203.

Ibáñez CM, Cubillos LA, Tafur R, Argueelles J, Yamashiro C, Poulin E. 2011. Genetic diversity and demographic history of Dosidicus gigas (Cephalopoda: Ommastrephidae) in the Humboldt Current System. Mar Ecol Prog Ser. 431:163-171.

Inaba A. 1959. Notes on the chromosomes of two species of octopods (Cephalopoda Mollusca). Jap J Genet. 34:137-139.

Ito K, Yanagimoto T, Iwata Y, Munehara H, Sakurai Y. 2006. Genetic population structure of the spear squid Loligo bleekeri based on mitochondrial DNA. Nippon Suisan Gakkaishi. 72:905-910.

Iwata Y, Munehara H, Sakurai Y. 2003. Characterization of microsatellite markers in the squid Loligo bleekeri (Cephalopoda: Loliginidae). Mol Ecol Notes. 3:392-393.

Iwata Y, Munehara H, Sakurai Y. 2005. Dependence of paternity rates on alternative reproductive behaviors in the squid Loligo bleekeri. Mar Ecol Prog Ser. 298:219-228.

Jazayeri A, Papan F, Motamedi H, Mahmoudi S. 2011. Karyological investigation of Persian Gulf cuttlefish (Sepia arabica) in the coasts of Khuzestan province. Life Sci J. 8:849-852.

Jones BW, Nishiguchi MK. 2004. Counterillumination in the bobtail squid, Euprymna scolopes (Mollusca: Cephalopoda). Mar Biol. 144:1151-1155.

Jones BW, Nishiguchi MK. 2006. Vibrio fischeri transcripts reveal adaptations in an environmentally transmitted symbiosis. Can J Microbiol. 52:1218-1227.

Jorgensen EM, Strugnell JM, Allcock AL. 2010. Description and phylogenetic relationships of a new genus of octopus Sasakiopus (Cephalopoda: Octopodidae) from the Bering Sea with a redescription of Sasakiopus salebrosus (Sasaki 1920). J Moll Stud. 76:57-66.

Juárez OE, Rosas C, Arena L. 2010. Heterologous microsatellites reveal moderate genetic structure in the Octopus maya population. Fish Res. 106:209-213.

Juárez OE, Rosas C, Arena-Ortiz ML. 2012. Phylogenetic relationships of Octopus maya revealed by mtDNA sequences. Cienc Mar. 38:563-575.

Kaneko N, Kubodera T, Dinh T, Chung BD. 2008. Shallow-water Benthic Octopuses (Cephalopoda Octopodidae) Collected from the Coastal Waters of Vietnam. Bull Natl Mus Nat Sci Zool. 34:105-122.

Kaneko N, Kubodera T, Iguchi A. 2011. Taxonomic study of shallow-water octopuses (Cephalopoda: Octopodidae) in Japan and adjacent waters using mitochondrial genes with perspectives on octopus DNA barcoding. Malacologia. 54:97-108.

Kang J-H, Kim Y-K, Park J-Y, An C-M, Jun J-C. 2012a. Development of microsatellite markers to genetically differentiate populations of Octopus minor from Korea and China. Mol Biol Rep. 39:8277-8286.

Kang J-H, Park J-Y, Choi T-J. 2012b. Genetic differentiation of octopuses from different habitats near the Korean Peninsula and eastern China based on analysis of the mDNA cytochrome C oxidase 1. Genet Mol Res. 11:3988-3997.

Kassahn KS, Donnellan SC, Fowler AJ, Hall KC, Adams M, Shaw PW. 2003. Molecular and morphological analyses of the cuttlefish Sepia apama indicate a complex population structure. Mar Biol. 143:947-962.

Keskin E, Atar HH. 2011. Genetic divergence of Octopus vulgaris species in the eastern Mediterranean. Biochem Syst Ecol. 39:277-282.

Keyl F, Wolff M, Arugelles J, Marategui L, Tafur R, Yamshiro C. 2008. A hypothesis on range expansion and spatio-temporal shifts in size-at-maturity of jumbo squid (Dosidicus gigas) in the eastern Pacific Ocean. Cal Coop Ocean Fish Invest Rep. 49:119-128.

Khromov DN, Lu CC, Guerra A, Dong Z, Boletzky Sv. 1998. A synopsis of Sepiidae outside Australian waters. Smithson Contr Zool. 586:77-156. 
Kimbell JR, McFall-Ngai MJ. 2003. The squid-vibrio symbioses: from demes to genes. Int Comp Biol. 43:254-260.

Kitaura J, Yamamoto G, Nishida M. 1998. Genetic variation in populations of the diamondshaped squid Thysanoteuthis rhombus as examined by mitochondrial DNA sequence analysis. Fish Sci. 64:538-542.

Kocot KM, Cannon JT, Todt C, Citarella MR, Kohn AB, Meyer A, Santos SR, Schander C, Moroz LL, Lieb B, et al. 2011. Phylogenomics reveals deep molluscan relationships. Nature. 477:452-456.

Kröger B, Vinther J, Fuchs D. 2011. Cephalopod origin and evolution: A congruent picture emerging from fossils, development and molecules. Bioessays. 33:602-613.

Kurosaka K, Yanagimoto T, Wakabayashi T, Shigenobu Y, Ochi Y, Inada H. 2012. Population genetic structure of the neon flying squid Ommastrephes bartramii inferred from mitochondrial DNA sequence analysis. Nippon Suisan Gakkaishi. 78:212-219.

Leite TS, Haimovici M, Molina W, Warnke K. 2008. Morphological and genetic description of Octopus insularis a new cryptic species in the Octopus vulgaris complex (Cephalopoda: Octopodidae) from the tropical southwestern Atlantic. J Moll Stud. 74:63-74.

Lieb B, Mark1 J. 2004. Evolution of molluscan hemocyanins as deduced from DNA sequencing. Micron. 35:117-119.

Lin XZ, Zheng XD, Xiao S, Wang RC. 2004. Phylogeny of the cuttlefishes (Mollusca: Cephalopoda) based on mitochondrial COI and 16S rRNA gene sequence data. Acta Oceanolog Sin. 23:699-707.

Lindgren AR. 2010. Molecular inference of phylogenetic relationships among Decapodiformes (Mollusca: Cephalopoda) with special focus on the squid Order Oegopsida. Mol Phylogenet Evol. 56:77-90.

Lindgren AR, Daly M. 2007. The impact of length-variable data and alignment criterion on the phylogeny of Decapodiformes (Mollusca: Cephalopoda). Cladistics. 23:464-476.

Lindgren AR, Giribet G, Nishiguchi MK. 2004. A combined approach to the phylogeny of Cephalopoda (Mollusca). Cladistics. 20:454-486.

Lindgren AR, Katugin ON, Amezquita E, Nishiguchi MK. 2005. Evolutionary relationships among squids of the family Gonatidae (Mollusca: Cephalopoda) inferred from three mitochondrial loci. Mol Phylogenet Evol. 36:101-111.

Lindgren AR, Pankey MS, Hochberg FG, Oakley TH. 2012. A multi-gene phylogeny of Cephalopoda supports convergent morphological evolution in association with multiple habitat shifts in the marine environment. BMC Evol Biol. 12:129.

Mallatt J, Craig CW, Yoder MJ. 2010. Nearly complete rRNA genes assembled from across the metazoan animals: Effects of more taxa a structure-based alignment and paired-sites evolutionary models on phylogeny reconstruction. Mol Phylogenet Evol. 55:1-17.

Mallatt J, Craig CW, Yoder MJ. 2012. Nearly complete rRNA genes from 371 Animalia: Updated structure-based alignment and detailed phylogenetic analysis. Mol Phylogenet Evol. 64:603-617.

Maxmen AB, King BF, Cutler EB, Giribet G. 2003. Evolutionary relationships within the protostome phylum Sipuncula: a molecular analysis of ribosomal genes and histone $\mathrm{H} 3$ sequence data. Mol Phylogenet Evol. 27(3):489-503.

Maxwell MR, Buresch KM, Hanlon RT. 2000. Pattern of inheritance of microsatellite loci in the squid Loligo pealeii (Mollusca: Cephalopoda). Mar Biotechnol. 2:517-521.

McFall-Ngai MJ. 1999. Consequences of evolving with bacterial symbionts: Insights from the squid-vibrio associations. Ann Rev Ecol Syst. 30:235-256.

McFall-Ngai MJ, Montgomery M. 1990. The anatomy and morphology of the adult bacterial light organ of Euprymna scolopes Berry (Cephalopoda: Sepiolidae). Biol Bull. 179:332-339.

Moreira AA, Comes TAR, Silva HAW. 2011. Evidence for genetic differentiation of Octopus vulgaris (Mollusca Cephalopoda) fishery populations from the southern coast of Brazil as revealed by microsatellites. J Exp Mar Biol Ecol. 407:34 40. 
Murphy JM, Baguerias E, Key LN, Boyle PR. 2002. Microsatellite DNA markers discriminate between two Octopus vulgaris (Cephalopoda: Octopoda) fisheries along the northwest African coast. Bull Mar Sci. 71:545-553.

Naef A. 1921/1923. Cephalopoda. Fauna e flora del Golfo di Napoli Monograph. (translated from German by the Israel Program for Scientific Translations Ltd, Jerusalem, 1972).

Nakamura HK. 1985. A review of molluscan cytogenetic information based on the CISMOCHComputerized Index System for molluscan chromosomes. Bivalvia, Polyplacophora and Cephalopoda. Venus. 44:193-225.

Naud MJ, Hanlon RT, Hall KC, Shaw PW, Havenhand JN. 2004. Behavioural and genetic assessment of reproductive success in a spawning aggregation of the Australian giant cuttlefish Sepia apama. Animal Behav. 67:1043-1050.

Naud M-J, Shaw PW. 2008. Isolation and characterization of highly polymorphic microsatellites in the chokka squid Loligo reynaudii. Mol Ecol. Resources. 8:943-945.

Naud MJ, Shaw PW, Hanlon RT, Havenhand JN. 2005. Evidence for biased use of sperm sources in wild female giant cuttlefish (Sepia apama). Proc Roy Soc B. 272:1047-1051.

Nigmatullin MC, Arkhipkin AI, Sabirov MR. 1995. Age growth and reproductive biology of diamond-shaped squid Thysanoteuthis rhombus (Oegopsida: Thysanoteuthidae). Mar Ecol Prog Ser. 124:73-87.

Nishiguchi MK. 2002. Host-symbiont regognition in the environmentally transmitted sepiolid squid-Vibrio mutualism. Microb Ecol. 44:10-18.

Nishiguchi MK, Lopez JE, Boletzky Sv. 2004. Enlightenment of old ideas from new investigations: The evolution of bacteriogenic light organs in squids. Evol Develop. 6:41-49.

Nishiguchi MK, Ruby EG, McFall-Ngai MJ. 1998. Competitive dominance among strains of luminous bacteria provides an unusual form of evidence for parallel evolution in sepiolid squid-vibrio symbioses. Appl Environ Microbiol. 64:3209-3213.

Norman MD, Hochberg FG, Lu CC. 1997. Mollusca: Cephalopoda: Mid-depth octopuses $(200-1000 \mathrm{~m})$ of the Banda and Arafura Seas (Octopodidae and Alloposidae). In: Crosnier A, Bouchet P, editors. Résultats des Campagnes MUSORSTOM Vol. 16. Mém Mus Natl Hist Nat. 172:357-383.

Nyholm SV, McFall-Ngai MJ. 2003. Dominance of Vibrio fischeri in secreted mucus outside the light organ of Euprymna scolopes: the first site of symbiont specificity. Appl Environ Microbiol. 69:3932-3937.

Nyholm SV, Nishiguchi MK. 2008. The evolutionary ecology of a sepiolid squid-Vibrio association: From cell to environment. Vie et Milieu. 58:175-184.

Ohama T, Kumazaki T, Hori H, Osawa S. 1984. Evolution of multicellular animals as deduced from $5 \mathrm{~s}$ ribosomal-RNA sequences - a possible early emergence of the Mesozoa. Nucleic Acids Res. 12:5101-5108.

Oosthuizen A, Jiwaji M, Shaw P. 2004. Genetic analysis of the Octopus vulgaris population on the coast of South Africa. S Afr J Sci. 100:603-607.

Papan F, Jazayeri A, Ebrahimipour M. 2010. The study of persian gulf cuttlefish (Sepia pharaonis) chromosome via incubation of blood cells. J Am Sci. 6:162-164.

Passamaneck YJ, Schander C, Halanych KM. 2004. Investigation of molluscan phylogeny using large-subunit and small-subunit nuclear rRNA sequences. Mol Phylogen Evol. 32:25-38.

Patterson CM. 1969. Chromosomes of Molluscs. Proceedings of the Symposium on Molluscans. Marine Biological Association India. 2:635-686.

Pérez-Losada M, Guerra A, Carvalho GR, Sanjuan A, Shaw PW. 2002a. Extensive population subdivision of the cuttlefish Sepia officinalis (Mollusca: Cephalopoda) around the Iberian Peninsula indicated by microsatellite DNA variation. Heredity. 89:417-424.

Pérez-Losada M, Guerra A, Sanjuan A. 2002b. Allozyme divergence supporting the taxonomic separation of Octopus mimus and Octopus maya from Octopus vulgaris (Cephalopoda: Octopoda). Bull Mar Sci. 71:653-664. 
Pérez-Losada M, Nolte MJ, Crandall KA, Shaw PW. 2007. Testing hypotheses of population structuring in the Northeast Atlantic Ocean and Mediterranean Sea using the common cuttlefish Sepia officinalis. Mol Ecol. 16:2667-2679.

Piertney SB, Hudelot C, Hochberg FG, Collins MA. 2003. Phylogenetic relationships among cirrate octopods (Mollusca: Cephalopoda) resolved using mitochondrial 16S ribosomal DNA sequences. Mol Phylogen Evol. 27:348-353.

Quinteiro J, Baibai T, Oukhattar L, Soukri A, Seixas P, Rey-Mendez M. 2011. Multiple paternity in the common octopus Octopus vulgaris (Cuvier 1797) as revealed by microsatellite DNA analysis. Moll Res. 31:15-20.

Ramirez SA, Zeagler JW, Landry L, Walker SD. 1979. Reproductive cycle histologicalhistopathological survey of gonadal tissue and karyotype analysis of selected species of macroepifauna and demersal fishes. Environmental studies south Texas outer continental shelf biology and chemistry. Volume II. Chapter 21. pp. 1-68. Report to the Bureau of Land Management by University of Texas Marine Science Institute Port Aransas Texas 21:1-68.

Ramos-Castillejos JE, Salinas-Zavala CA, Carmarillo-Coop S, Enriquez-Peredes LM. 2010. Paralarvae of the jumbo squid, Dosidicus gigas. Invertebr Biol. 129:172-183.

Reichow D, Smith MJ. 1999. Highly variable microsatellites in the California market squid Loligo opalescens. Mar Biotechnol. 1:403-406.

Reichow D, Smith MJ. 2001. Microsatellites reveal high levels of gene flow among populations of the California squid Loligo opalescens. Mol Ecol. 10:1101-1109.

Robson GC. 1932. A monograph of the recent Cephalopoda, Part II. Octopoda (excluding Octopodinae). British Museum Natural History, London. pp. 359.

Rosenberg G, Kuncio GS, Davis GM, Harasewych MG. 1994. Ribosomal RNA phylogeny of selected gastropod and unionacean bivalve mollusks. Nautilus. 108(Suppl. 2):111-121.

Rosenberg G, Tillier S, Tillier A, Kuncio GS, Hanlon RT, Masselot M, Williams CJ. 1997. Ribosomal RNA phylogeny of selected major clades in the Mollusca. J Moll Stud. 63:301-309.

Runnegar B, Pojeta J. 1974. Molluscan phylogeny: the paleontological viewpoint. Science. 186:311-317.

Runnegar B, Pojeta J. 1985. Origin and diversification of the Mollusca. In: Trueman ER, Clarke MR, editors. The Mollusca. Vol 10: Evolution. London: Academic Press; 1-57.

Runnegar B, Pojeta J. 1992. The earliest bivalves and their Ordovician descendents. Am Malacol Bull. 9:117-122.

Sales JBL, Shaw PW, Haimovici M, Markaida U, Cunha DB, Ready J, Figueiredo-Ready WMB, Schneider H, Sampaio I. 2013. New molecular phylogeny of the squids of the family Loliginidae with emphasis on the genus Doryteuthis Naef, 1912: mitochondrial and nuclear sequences indicate the presence of cryptic species in the southern Atlantic Ocean. Mol Phylogenet Evol. 68:293-299.

Salwini-Plawen Lv. 1980. A reconsideration of systematics in the Mollusca (phylogeny and higher classification). Malacologia. 19:249-278.

Salvini-Plawen Lv, G S. 1996. Synapomorphies and plesiomorphies in higher classification of Mollusca. In: Taylor JD, editor. Origin and evolutionary radiation of the Mollusca. Centenary Symposium of the Malacological Society of London. Oxford: Oxford University Press; 29-51.

Sands CJ, Jarman SN, Jackson GD. 2003. Genetic differentiation in the squid Moroteuthis ingens inferred from RAPD analysis. Polar Biol. 26:166-170.

Sasuga J, Yokobori S, Kaifu M, Ueda T, Nishikawa K, Watanabe K. 1999. Gene contents and organization of a mitochondrial DNA segment of the squid Loligo bleekeri. J Mol Evol. 48:692-702.

Scheltema AH. 1993. Aplacophora as progenetic aculiferans and the coelomate origin of mollusks as the sister taxon of Sipuncula. Biol Bull. 184:57-78. 
Seibel BA, Hochberg FG, Carlini DB. 2000. Life history of Gonatus onyx (Cephalopoda: Teuthoidea): deep-sea spawning and post-spawning egg care. Mar Biol. 137:519-526.

Shaw PW. 1997. Polymorphic microsatellite markers in a cephalopod: The veined squid Loligo forbesi. Mol Ecol. 6:297-333.

Shaw PW. 2002. Past, present and future applications of DNA-based markers in cephalopod biology: Workshop report. Bull Mar Sci. 71:67-78.

Shaw PW. 2003. Polymorphic microsatellite DNA markers for the assessment of genetic diversity and paternity testing in the giant cuttlefish Sepia apama (Cephalopoda). Conserv Genet. 4:533-535.

Shaw PW, Adcock GJ. 2002. Polymorphic microsatellite DNA markers for the Patagonian squid Loligo gahi (Cephalopoda). Mol Ecol. Notes. 2:331-333.

Shaw PW, Arkhipkin AI, Adcock GJ, Burnett WJ, Carvalho GR, Scherbich JN, Villegas PA. 2004. DNA markers indicate that distinct spawning cohorts and aggregations of Patagonian squid Loligo gahi do not represent genetically discrete subpopulations. Mar Biol. 144:961-970.

Shaw PW, Boyle PR. 1997. Multiple paternity within the brood of single females of Loligo forbesi (Cephalopoda: Loliginidae) demonstrated with microsatellite DNA markers. Mar Ecol Prog Ser. 160:279-282.

Shaw PW, Hendrickson L, McKeown NJ, Stonier T, Naud MJ, Sauer WHH. 2010. Discrete spawning aggregations of loliginid squid do not represent genetically distinct populations. Mar Ecol Prog Ser. 408:117-127.

Shaw PW, Pierce GJ, Boyle PR. 1999. Subtle population structuring within a highly vagile marine invertebrate the veined squid Loligo forbesi demonstrated with microsatellite DNA markers. Mol Ecol. 8:407-417.

Shaw PW, Pérez-Losada M. 2000. Polymorphic microsatellites in the common cuttlefish Sepia officinalis (Cephalopoda). Mol Ecol. 9:237-238.

Shaw PW, Sauer WHH. 2004. Multiple paternity and complex fertilisation dynamics in the squid Loligo vulgaris reynaudii. Mar Ecol Prog Ser. 270:173-179.

Shimodaira H. 2002. An approximately unbiased test of phylogenetic tree selection. Syst Biol. 51(3):492-508.

Sigwart JD, Sutton MD. 2007. Deep molluscan phylogeny: Synthesis of palaeontological and neontological data. Proc Roy Soc B. 274:2413-2419.

Sin YW, Yau C, Chu KH. 2009. Morphological and genetic differentiation of two loliginid squids Uroteuthis (Photololigo) chinensis and Uroteuthis (Photololigo) edulis (Cephalopoda: Loliginidae) in Asia. J Exp Mar Biol Ecol. 369:22-30.

Sinclair B, Briskey L, Aspden W, Pegg G. 2007. Genetic diversity of isolated populations of Nautilus pompilius (Mollusca Cephalopoda) in the Great Barrier Reef and Coral Sea. Rev Fish Biol Fish. 17:223-235.

Sinclair W, Newman SJ, Vianna GMS, Williams S, Aspden WJ. 2011. Spatial subdivision and genetic diversity in populations on the east and west coasts of Australia: the multi-faceted case of Nautilus pompilius (Mollusca Cephalopoda). Rev Fish Sci. 19:52-61.

Smith SA, Wilson NG, Goetz FE, Feehery C, Andrade SCS, Rouse GW, Giribet G, Dunn CW. 2011. Resolving the evolutionary relationships of molluses with phylogenomic tools. Nature. 480:364.

Staaf DJ, Redfern JV, Gilly WF, Watson W, Balance LT. 2013. Distribution of ommastrephid paralarvae in the eastern tropical Pacific. Fish Bull. 111:78-89.

Staaf DJ, Ruiz-Cooley RI, Elliger C, Lebaric Z, Campos B, Markaida U, Gilly WF. 2010. Ommastrephid squids Sthenoteuthis oualaniensis and Dosidicus gigas in the eastern Pacific show convergent biogeographic breaks but contrasting population structures. Mar Ecol Prog Ser. 418:165-178.

Steiner G, Dreyer H. 2003. Molecular phylogeny of Scaphopoda (Mollusca) inferred from 18 S rDNA sequences: support for a Scaphopoda-Cephalopoda clade. Zool Scripta. $32: 343-356$. 
Strugnell J, Allcock AL. 2010. Co-estimation of phylogeny and divergence times of Argonautoidea using relaxed phylogenetics. Mol Phylogen Evol. 54:701-708.

Strugnell JM, Allcock AL, Watts PC. 2009b. A panel of microsatellite loci from two species of octopus, Pareledone turqueti (Joubin 1905) and Pareledone charcoti (Joubin 1905). Mol Ecol. Resour. 9:1239-1242.

Strugnell JM, Allcock AL, Watts PC. 2009c. Microsatellite loci from the endemic Southern Ocean octopus Adelieledone polymorpha (Robson 1930). Mol Ecol. Resour. 9:1068-1070.

Strugnell JM, Cherel Y, Cooke IR, Gleadall IG, Hochberg FG, Ibanez CM, Jorgensen E, Laptikhovsky VV, Linse K, Norman M, et al. 2011. The Southern Ocean: Source and sink?. Deep-Sea Res II. 58:196-204.

Strugnell JM, Collins MA, Allcock AL. 2008b. Molecular evolutionary relationships of the octopodid genus Thaumeledone (Cephalopoda: Octopodidae) from the Southern Ocean. Antarct Sci. 20:245-251.

Strugnell J, Jackson J, Drummond AJ, Cooper A. 2006a. Divergence time estimates for major cephalopod groups: evidence from multiple genes. Cladistics. 22:89-96.

Strugnell JM, Lindgren AR. 2007. A barcode of life database for the Cephalopoda? Considerations and concerns. Rev Fish Biol Fish. 17:337-344.

Strugnell J, Nishiguchi MK. 2007. Molecular phylogeny of coleoid cephalopods (Mollusca: Cephalopoda) inferred from three mitochondrial and six nuclear loci: A comparison of alignment, implied alignment and analysis methods. J Moll Stud. 73:399-410.

Strugnell J, Norman M, Cooper A. 2006b. DNA from beach-washed shells of the ram's horn squid Spirula spirula. Bull Mar Sci. 78:389-391.

Strugnell J, Norman M, Drummond AJ, Cooper A. 2004. Neotenous origins for pelagic octopuses. Curr Biol. 14:R300-R301.

Strugnell J, Norman M, Jackson J, Drummond AJ, Cooper A. 2005. Molecular phylogeny of coleoid cephalopods (Mollusca: Cephalopoda) using a multigene approach, the effect of data partitioning on resolving phylogenies in a Bayesian framework. Mol Phylogen Evol. $37: 426-441$.

Strugnell J, Norman MD, Vecchione M, Guzik M, Allcock AL. 2013. The ink sac clouds octopod evolutionary history. Hydrobiologia. http://link.springer.com/article/10.1007\% 2Fs10750-013-1517-6

Strugnell JM, Rogers AD, Prodohl PA, Collins MA, Allcock AL. 2008a. The thermohaline expressway: the Southern Ocean as a centre of origin for deep-sea octopuses. Cladistics. 24:853-860.

Strugnell J, Voight JR, Collins PC, Allcock L. 2009a. Molecular phylogenetic analysis of a known and a new hydrothermal vent octopod: their relationships with the genus Benthoctopus (Cephalopoda: Octopodidae). Zootaxa. 2096:442-459.

Strugnell JM, Watts PC, Allcock AL. 2012. Persistent genetic signatures of historic climatic events in an Antarctic octopus. Mol Ecol. 21:2775-2787.

Sweeney MJ, Roper CFE. 1998. Classification, type localities and type repositories of Recent Cephalopoda. Smithson Contr Zool. 586:561-599.

Söller R, Warnke K, Saint-Paul U, Blohm D. 2000. Sequence divergence of mitochondrial DNA indicates cryptic biodiversity in Octopus vulgaris and supports the taxonomic distinctiveness of Octopus mimus (Cephalopoda: Octopodidae). Mar Biol. 136:29-35.

Takemoto K, Yamashita M. 2012. Complete nucleotide sequences of mitochondrial DNA of long-finned squid Loligo edulis. Fish Sci. 78:1031-1039.

Takumiya M, Kobayashi M, Tsuneki K, Furuya H. 2005. Phylogenetic relationships among major species of Japanese coleoid cephalopods (Mollusca: Cephalopoda) using three mitochondrial DNA sequences. Zool Sci. 22:147-155.

Teske PR, Oosthuizen A, Papadopoulos I, Barker NP. 2007. Phylogeographic structure of Octopus vulgaris in South Africa revisited: identification of a second lineage near Durban harbour. Mar Biol. 151:2119-2122. 
Tomita K, Yokobori S, Oshima T, Ueda T, Watanabe K. 2002. The cephalopod Loligo bleekeri mitochondrial genome: Multiplied noncoding regions and transposition of tRNA genes. $\mathrm{J}$ Mol Evol. 54:486-500.

Toussaint RK, Scheel D, Sage GK, Talbot SL. 2012. Nuclear and mitochondrial markers reveal evidence for genetically segregated cryptic speciation in giant Pacific octopuses from Prince William Sound, Alaska. Conserv Genet. 13:1483-1497.

Turan C, Yaglioglu D. 2010. Population identification of common cuttlefish (Sepia officinalis) inferred from genetic morphometric and cuttlebone chemistry data in the NE Mediterranean Sea. Sci Marina. 74:77-86.

Undheim EAB, Norman JA, Thoen HH, Fry BG. 2010. Genetic identification of Southern Ocean octopod samples using mtCOI. Compt Rend Biol. 333:395-404.

van Camp LM, Donnellan SC, Dyer AR, Fairweather PG. 2004. Multiple paternity in field- and captive-laid egg strands of Sepioteuthis australis (Cephalopoda: Loliginidae). Mar Freshw Res. 55:819-823.

van Camp LM, Saint KM, Donnellan S, Havenhand JN, Fairweather PG. 2003. Polymorphic microsatellite markers for paternity assessment in southern calamari Sepioteuthis australis (Cephalopoda: Loliginidae). Mol Ecol. Notes. 3:654-655.

Vecchione M, Allcock L, Piatkowski U, Strugnell J. 2009. Benthoctopus rigbyae, n. sp., a new species of cephalopod (Octopoda, Incirrata) from near the Antarctic Peninsula. Malacologia. 51:13-28.

Vecchione M, Shea E, Bussarawit S, Anderson F, Alexeyev D, Lu CC, Okutani T, Roeleveld M, Chotiyaputta C, Roper C, et al. 2005. Systematics of Indo-West Pacific loliginids. Phuket Mar Biol Center Res Bull. 66:23-36.

Vecchione M, Young RE, Carlini DB. 2000. Reconstruction of ancestral character states in neocoleoid cephalopods based on parsimony. Am Malacol Bull. 15:179-193.

Visick KL, McFall-Ngai MJ. 2000. An exclusive contract: specificity in the Vibrio fischeriEuprymna scolopes partnership. J Bacteriol. 182:1779-1787.

Vitturi R, Colombera D, Catalano E, Arnold JM. 1990. Spermatocyte chromosome study of eight species of the class Cephalopoda (Mollusca. J Cephalopod Biol. 1:101-112.

Vitturi R, Rasotto MB, Farinella-Ferruzza N. 1982. The chromosomes of 16 molluscan species. Boll Zool. 49:61-71.

Voight JR, Feldheim KA. 2009. Microsatellite inheritance and multiple paternity in the deep-sea octopus Graneledone boreopacifica (Mollusca: Cephalopoda). Invert Biol. 128:26-30.

Wada S, Ichii T, Sakai M. 2002. Sequence comparison of 16S rRNA among six ommastrephids. Report on the 2000 Meeting of Squid Resources. Nat Res Inst Far Seas Fish Shizuoka. 2002, 78-79. [In Japanese].

Wakabayashi T, Kubodera T, Sakai M, Ichii T, Chow S. 2007. Molecular evidence for synonymy of the genera Moroteuthis and Onykia and identification of their paralarvae from northern Hawaiian waters. J Mar Biol Assoc UK. 87:959-965.

Wakabayashi T, Suzuki N, Sakai M, Ichii T, Chow S. 2006. Identification of ommastrephid squid paralarvae collected in northern Hawaiian waters and phylogenetic implications for the family Ommastrephidae using mtDNA analysis. Fish Sci. 72:494-502.

Wakabayashi T, Suzuki N, Sakai M, Ichii T, Chow S. 2012a. Phylogenetic relationships among the family Ommastrephidae (Mollusca: Cephalopoda) inferred from two mitochondrial DNA gene sequences. Mar Genomics. 7:11-16.

Wakabayashi T, Wada S, Ochi Y, Ichii T, Sakai M. 2012b. Genetic differentiation of the neon flying squid Ommastrephes bartramii between North Pacific and South Atlantic populations. Nippon Suisan Gakkaishi. 78:198-203.

Walker WF, Doolittle WF. 1983. 5S ribosomal-RNA sequences from four marine-invertebrates and implications for base-pairing models of metazoan sequences. Nucleic Acids Res. 11:5159-5164. 
Warnke K. 2007. On the species status of Spirula spirula (Linné, 1758) (Cephalopoda): a new approach based on divergence of amino acid sequences between the Canaries and New Caledonia. In: Landman NH, Davis RA, Mapes RH, editors. Cephalopods Present and Past: New Insights and Fresh Perspectives. Dordrecht: Springer; 144-155.

Warnke KM, Meyer A, Ebner B, Lieb B. 2011. Assessing divergence time of Spirulida and Sepiida (Cephalopoda) based on hemocyanin sequences. Mol Phylogenet Evol. 58:390-394.

Warnke K, Plötner J, Santana JI, Rueda MJ, Llinás O. 2001. Zur Phylogenie rezenter Cephalopoden- Erste Ergebnisse einer molekulargenetischen Analyse des 18S rRNA-Gens. Berliner Geowiss Abh E. 36:169-172.

Warnke K, Plötner J, Santana JI, Rueda MJ, Llinas O. 2003. Reflections on the phylogenetic position of Spirula (Cephalopoda): Preliminary evidence from the 18S ribosomal RNA gene. Berliner Paläobiol Abh. 3:253-260.

Warnke K, Söller R, Blohm D, Saint-Paul U. 2000. Rapid differentiation between Octopus vulgaris Cuvier (1797) and Octopus mimus Gould (1852) using randomly amplified polymorphic DNA. J Zool Syst Evol Res. 38:119-122.

Warnke K, Söller R, Blohm D, Saint-Paul U. 2004. A new look at geographic and phylogenetic relationships within the species group surrounding Octopus vulgaris (Mollusca Cephalopoda): indications of very wide distribution from mitochondrial DNA sequences. J Zool Syst Evol Res. 42:306-312.

Wheeler W. 1996. Optimization alignment: The end of multiple sequence alignment in phylogenetics?. Cladistics. 12:1-9.

Wheeler WC, Gladstein D, DeLaet J. 2002. POY, Version 3.0. Program and documentation available from: ftp://ftp.amnh.org/pub/molecular. American Museum of Natural History.

Wheeler WC, Hayashi C. 1998. The phylogeny of extant chelicerate orders. Cladistics. 24:13-192.

Williams RC, Newman SJ, Sinclair W. 2012. DNA barcoding in Nautilus pompilius (Mollusca: Cephalopoda): evolutionary divergence of an ancient species in modern times. Invert Syst. 26:548-560.

Wilson NG, Rouse GW, Giribet G. 2010. Assessing the molluscan hypothesis Serialia (Monoplacophora + Polyplacophora) using novel molecular data. Mol Phylogenet Evol. 54:187-193.

Winklemann I, Campos PF, Strugnell J, Cherel Y, Smith PJ, Kubodera T, Allcock L, Kampmann M-L, Schroeder H, Guerra A, et al. 2013. Mitochondrial genome diversity and population structure of the gian squid Architeuthis: genetics sheds new light on one of the most enigmatic marine species. Proc Roy Soc B. 280:20130273.

Winnepenninckx B, Backeljau T, DeWachter R. 1996. Investigation of molluscan phylogeny on the basis of 18S rRNA sequences. Mol Biol Evol. 13:1306-1317.

Wolfram K, Mark FC, John U, Lucassen M, Poertner HO. 2006b. Microsatellite DNA variation indicates low levels of genetic differentiation among cuttlefish (Sepia officinalis L.) populations in the English Channel and the Bay of Biscay. Comp Biochem Physiol D. 1:375-383.

Wolfram K, Mark F, Portner H. 2006a. Microsatellite DNA variation indicates a panmictic population of the cuttlefish Sepia officinalis (Mollusca: Cephalopoda) in the English Channel and the Bay of Biscay. Comp Biochem Physiol A. 143:S64.

Wu C, Chi C, He G, Lue Z, Xu M. 2010. Isolation via enrichment and characterization of ten polymorphic microsatellite loci in the cuttlefish Sepiella maindroni de Rochebruns. Acta Oceanolog Sin. 29:121-124.

Yokobori S, Fukuda N, Nakamura M, Aoyama T. 2004. Long-term conservation of six duplicated structural genes in cephalopod mitochondrial genomes. Mol Biol Evol. 21:2034-2046. 
Yokobori S-I, Lindsay DJ, Tsuchiya K, Yaniagishi A, Maruyama T, Shirna T. 2007. Mitochondrial genome structure and evolution in the living fossil vampire squid Vampyroteuthis infernalis and extant cephalopods. Mol Phylogenet Evol. 44:898-910.

Yoshida MA, Ishikura Y, Moritaki T, Shoguchi E, Shimizu KK, Sese J, Ogura A. 2011. Genome structure analysis of molluscs revealed whole genome duplication and lineage specific repeat variation. Gene. 483:63-71.

Yoshida M, Tsuneki K, Furuya H. 2006. Phylogeny of selected Sepiidae (Mollusca Cephalopoda) based on $12 \mathrm{~S}, 16 \mathrm{~S}$, and COI sequences, with comments on the taxonomic reliability of several morphological characters. Zool Sci. 23:341-351.

Yoshida M, Tsuneki D, Furuya H. 2010. Molecular phylogeny among East-Asian cuttlefishes using three mitochondrial genes. In: Tanabe K, Shigeta Y, Sasaki T, Hirano H, editors. Cephalopods Present and Past: New Insights and Fresh Perspectives. Dordrecht: Springer; 144-155.

Young RE, Vecchione M. 1999. Morphological observations on a hatchling and a paralarva of the vampire squid Vampyroteuthis infernalis Chun (Mollusca Cephalopoda). Proc Biol Soc Wash. 112:661-666.

Young RE, Vecchione M. 2008. Chiroteuthid families. Version 21 April 2008 (under construction). Available from: http://tolweb.org/Chiroteuthid_families/19410/2008.04.21 in The Tree of Life Web Project, http://tolweb.org/

Young RE, Vecchione M, Mangold KM. 2012. Cephalopoda Cuvier 1797. Octopods, squids, nautiluses, etc. Version 10 November 2012 (under construction). Available from: http://tolweb.org/Cephalopoda/19386/2012.11.10 in The Tree of Life Web Project, http://tolweb.org/

Zamborsky DJ, Nishiguchi MK. 2011. Phylogeographical patterns among mediterranean sepiolid squids and their vibrio symbionts: environment drives specificity among sympatric species. Appl Environ Microbiol. 77:642-649.

Zheng X, Ikeda M, Barinova A, Taniguchi N. 2007. Isolation and characterization of microsatellite DNA loci from the golden cuttlefish Sepia esculenta Hoyle (Cephalopoda). Mol Ecol Notes. 7:40-42.

Zheng X, Ikeda M, Kong L, Lin X, Li Q, Taniguchi N. 2009. Genetic diversity and population structure of the golden cuttlefish Sepia esculenta (Cephalopoda: Sepiidae) indicated by microsatellite DNA variations. Mar Ecol Evol Perspect. 30:448-454.

Zheng XD, Li Q, Wang Z, Yu R, Tian C, Wang R. 2005. Genetic diversity in populations of Sepiella japonica based on the mitochondrial DNA sequence analysis. Phuket Mar Biol Cent Res Bull. 66:195-201.

Zheng X, Lin X, Lu CC, Ma R. 2012a. A new species of Cistopus Gray 1849 (Cephalopoda: Octopodidae) from the East and South China Seas and phylogenetic analysis based on the mitochondrial COI gene. J Nat Hist. 46:355-368.

Zheng XD, Wang RC, Wang XF, Xiao S, Chen B. 2001. Genetic variation in populations of the common Chinese cuttlefish Sepiella maindroni (Mollusca: Cephalopoda) using allozymes and mitochondrial DNA sequence analysis. J Shellfish Res. 20:1159-1165.

Zheng XD, Yang JM, Lin XZ, Wang RC. 2004. Phylogenetic relationships among the Decabrachia cephalopods inferred from mitochondrial DNA sequences. J Shellfish Res. 23:881-886.

Zheng XD, Zuo ZR, Su XJ, Li Q. 2012b. Isolation and characterization of 24 polymorphic microsatellite loci in Sepioteuthis lessoniana. Genet Mol Res. 11:3961-3965.

Zuo Z, Zheng X, Liu C, Li Q. 2012. Development and characterization of 17 polymorphic microsatellite loci in Octopus vulgaris Cuvier, 1797. Conserv Genet Resour. 4:367-369.

Zuo ZR, Zheng XD, Yuan Y, Li Q. 2011. Development and characterization of 12 polymorphic microsatellite loci in Octopus minor (Sasaki, 1920). Conserv Genet Resour. 3:489-491. 